\title{
Fuzzy Control for Seismic Protection of Semiactive Base-Isolated Structures Subjected to Near-Fault Earthquakes
}

\author{
Dahai Zhao and Yongxing Li \\ School of Civil Engineering and Mechanics, Yanshan University, No. 438 Hebei Road, Qinhuangdao, Hebei, China \\ Correspondence should be addressed to Dahai Zhao; zhaodh@ysu.edu.cn
}

Received 22 October 2015; Accepted 6 December 2015

Academic Editor: Filippo Ubertini

Copyright ( 2015 D. Zhao and Y. Li. This is an open access article distributed under the Creative Commons Attribution License, which permits unrestricted use, distribution, and reproduction in any medium, provided the original work is properly cited.

\begin{abstract}
This paper proposes a new fuzzy logic controller, which is designed for seismic protection of base-isolated structures utilizing piezoelectric friction damper against near-fault earthquakes for different ground sites. According to the elastic design spectrum that Eurocode 8 recommends, one 5\% damped elastic design spectrum for Chi-Chi earthquake is proposed to generate artificial earthquakes of different ground sites. The proposed controller employs a hierarchic fuzzy control algorithm, in which a supervisory fuzzy controller governs a sublevel fuzzy controller by altering its input normalization factors according to current level of ground motion. In order to simultaneously reduce the base displacement and superstructure responses of the base-isolated structure during seismic excitations, genetic algorithm is employed to optimize the supervisory fuzzy controller and the preload of piezoelectric friction damper. The efficiency of the proposed controller is also compared with passive controller and a linear quadratic Gauss optimal controller. Numerical results show that the proposed fuzzy logic controller has favorable performance in mitigating the responses of the base-isolated structure.
\end{abstract}

\section{Introduction}

Base isolation has been demonstrated to be an effective technique that is used in seismic protection of crucial civil engineering structures. In order to mitigate the displacement of base-isolated structures, some designers usually installed dampers on isolation floor [1]. However, the performance of base-isolated structures against near-fault earthquakes has been questioned by several researchers $[2,3]$. Near-fault earthquakes have the characteristic of long duration pulses with peak velocities in contrast to far-field earthquakes $[4,5]$. Also, the long period of near-fault earthquakes coincides with the fundamental period of the base-isolated buildings $[6,7]$. Therefore, near-fault earthquakes possess much larger collapsing force for base-isolated structures than far-field earthquakes on account of resonance effect. Among the nearfault earthquakes in recent years, Chi-Chi earthquake has attracted an attention in the field of seismic engineering for its unique motion characteristics and great damage to civil engineering structures. This near-fault earthquake caused more than two thousand people deaths and wreaked havoc on the public property owing to the reverse oblique fractures in crustal rocks. During the Chi-Chi earthquake occurrence, scientists collected a large number of seismic records for different ground sites. Consequently, it is essential to design an appropriate control strategy to protect baseisolated structure under near-fault earthquakes for different ground sites.

Although the supplement of dampers could reduce the damage of base-isolated systems against strong earthquake excitations, it may also abuse large damping forces and cause significant magnifications on the acceleration and interstory drift of the base-isolated structure $[8,9]$. Semiactive control is an intelligent control algorithm, which can regulate the output power of dampers according to current condition of structure responses. Therefore, semiactive control has better adaptability than traditional passive control. Furthermore, semiactive control requires less power as compared to active control, which uses some powerful actuators to achieve ideal effects. For these reasons, many researchers have put forward all kinds of semiactive strategies for seismic protection. In these semiactive algorithms, fuzzy logic control has been a promising strategy, because it has the superiority in dealing with uncertain, complex, and nonlinear systems [10]. 


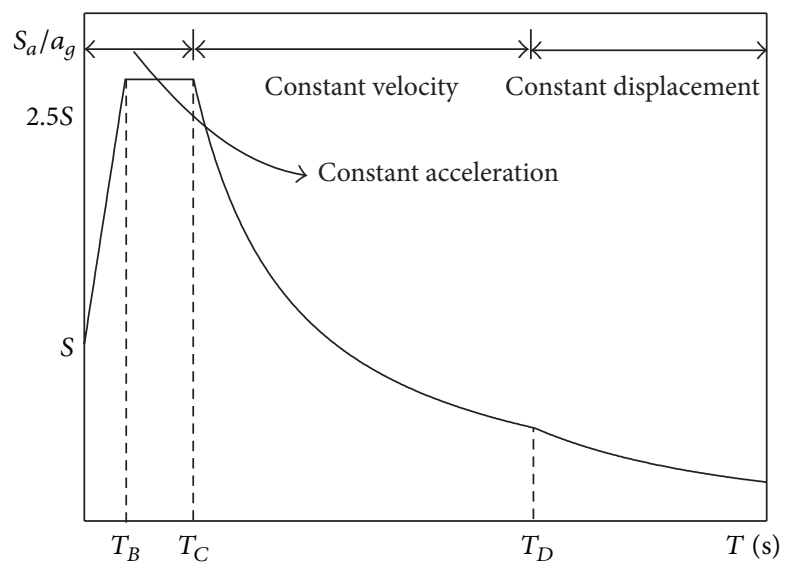

FIGURE 1: Design spectrum envelope for Chi-Chi earthquake.

Das et al. [11] studied fuzzy control for seismic protection of civil engineering structures using MR dampers. Wang and Lee [12] used genetic algorithm to optimize fuzzy rule to improve the performance of fuzzy control method. To deal with near-fault and far-field earthquake excitations, Reigles and Symans [13] proposed a supervisory fuzzy controller to regulate two lower-level fuzzy controllers. Kim and Roschke [14] proposed GA-fuzzy control method for smart base-isolated benchmark building using supervisory control method.

In this study, an improved fuzzy control is proposed for seismic protection of base-isolated building with piezoelectric friction damper subjected to near-fault earthquakes of different ground sites. According to the elastic design spectrum of the Eurocode 8 recommendation, a 5\% damping ratio elastic design spectrum for Chi-Chi earthquake is proposed to generate artificial earthquakes for different ground sites. The proposed fuzzy controller employs a hierarchic fuzzy control algorithm, which includes a supervisory fuzzy controller and a sublevel fuzzy controller to alter its input normalization factors according to the current level of ground motions. The sublevel fuzzy control is to determine the command voltage of piezoelectric friction damper according to the velocity and displacement of the base isolation. In order to simultaneously reduce the base displacement and superstructure responses of the base-isolated structure, genetic algorithm is employed to optimize the supervisory fuzzy control and preload of piezoelectric friction damper. For comparison, the proposed fuzzy controller is also investigated with passive and linear quadratic Gauss optimal controller. A series of time history analyses of a base-isolated structure under seismic excitations are also conducted to evaluate the performance of the developed controller.

\section{Generate Artificial Earthquakes for Different Ground Sites}

2.1. Elastic Design Spectrum for Chi-Chi Earthquake. In order to investigate the distinctive characteristics of near-fault earthquakes, some researchers have evaluated the performance of the near-fault earthquakes and proposed several judgment criterions. Yang and Zhao [15] proposed a judgment for near-fault earthquakes. The principles are listed as follows. Firstly, the ratio between PGV (Peak Ground Velocity) and PGA (Peak Ground Acceleration) is greater than $0.2 \mathrm{~s}$. Secondly, the Joyner-Boore distance is between 0 and $15 \mathrm{Km}$. Thirdly, the earthquake should possess obvious pulses with peak velocity. Based on the above principles, 29 seismic waves for Chi-Chi earthquake under different ground sites are selected from PEER database to generate elastic design spectrum. In the late 1980s, the European Committee for Standardization released the first European code, which contained structure design rules and minimum standards for earthquake resistant design. With constant renovation for recent years, Eurocode 8 code includes detailed investigation and research on seismic design parameters of different regions. So, this code has become the most authoritative and influential standard in the world [16]. According to the elastic design spectrum that Eurocode 8 code recommends, a $5 \%$ damping ratio elastic design spectrum for Chi-Chi earthquakes is proposed to generate artificial earthquakes for different ground sites.

The acceleration response spectral $S_{a}(T)$, as shown in Figure 1, can be given as follows:

$$
\begin{aligned}
& S_{a}(T)=a_{g} \cdot S \cdot\left[1+\frac{T}{T_{B}}(2.5-1)\right], \quad 0 \leq T \leq T_{B}, \\
& S_{a}(T)=a_{g} \cdot S \cdot 2.5, \quad T_{B} \leq T \leq T_{C}, \\
& S_{a}(T)=a_{g} \cdot S \cdot 2.5 \cdot\left(\frac{T_{C}}{T}\right)^{\alpha}, \quad T_{C} \leq T \leq T_{D}, \\
& S_{a}(T)=a_{g} \cdot S \cdot 2.5 \cdot\left(\frac{T_{C}}{T}\right)^{\alpha}\left(\frac{T_{D}}{T}\right)^{\beta}, \quad T_{D} \leq T,
\end{aligned}
$$

where $a_{g}$ is the design PGA of Chi-Chi earthquake, $S$ is the amplification coefficient for different site conditions, the corner periods $T_{B}, T_{C}$, and $T_{D}$ represent constant acceleration, constant velocity, and constant displacement spectral region, and $\alpha$ and $\beta$ are dimensionless indexes, respectively. 
TABLE 1: Selected Chi-Chi near-fault earthquakes.

\begin{tabular}{|c|c|c|c|c|c|c|c|c|}
\hline Earthquake & Station & $V_{s}(\mathrm{~m} / \mathrm{s})$ & PGA (g) & $\mathrm{PGV}(\mathrm{cm} / \mathrm{s})$ & PGD $(\mathrm{cm})$ & PGV/PGA & $\begin{array}{l}\text { Joyner-Boore } \\
\text { distance }(\mathrm{Km})\end{array}$ & Site classification \\
\hline \multirow{29}{*}{ Chi-Chi } & TCU110 & 212.72 & 0.18061 & 52.004 & 31.216 & 0.29 & 11.58 & \multirow{6}{*}{ Soft soil } \\
\hline & CHY101 & 258.89 & 0.3829 & 91.28 & 60.731 & 0.24 & 9.94 & \\
\hline & TCU123 & 270.22 & 0.1468 & 37.5 & 30.87 & 0.26 & 14.91 & \\
\hline & TCU051 & 350.06 & 0.19428 & 42.378 & 57.953 & 0.22 & 7.64 & \\
\hline & TCU060 & 375.42 & 0.14895 & 41.859 & 50.693 & 0.29 & 8.51 & \\
\hline & TCU101 & 389.41 & 0.23429 & 56.319 & 62.133 & 0.25 & 2.11 & \\
\hline & TCU056 & 403.2 & 0.15539 & 38.959 & 47.705 & 0.26 & 10.48 & \multirow{23}{*}{ Medium soil } \\
\hline & TCU104 & 410.45 & 0.10059 & 43.351 & 46.291 & 0.44 & 12.87 & \\
\hline & CHY024 & 427.73 & 0.22957 & 46.42 & 42.303 & 0.21 & 9.62 & \\
\hline & TCU106 & 451.37 & 0.15421 & 38.177 & 30.958 & 0.25 & 14.97 & \\
\hline & TCU053 & 454.55 & 0.18717 & 43.092 & 61.802 & 0.23 & 5.95 & \\
\hline & TCU054 & 460.69 & 0.17207 & 45.145 & 68.386 & 0.27 & 5.28 & \\
\hline & TCU136 & 462.1 & 0.16921 & 48.291 & 53.37 & 0.29 & 8.27 & \\
\hline & TCU082 & 472.81 & 0.19836 & 51.229 & 69.534 & 0.26 & 5.16 & \\
\hline & TCU063 & 476.14 & 0.15751 & 63.518 & 46.961 & 0.41 & 9.78 & \\
\hline & TCU049 & 487.27 & 0.25431 & 56.23 & 69.733 & 0.23 & 3.76 & \\
\hline & TCU068 & 487.34 & 0.46625 & 256.62 & 365.92 & 0.56 & 0.4 & \\
\hline & TCU116 & 493.09 & 0.15476 & 42.122 & 35.828 & 0.28 & 12.38 & \\
\hline & TCU103 & 494.1 & 0.15845 & 52.488 & 50.567 & 0.34 & 6.08 & \\
\hline & TCU100 & 535.13 & 0.11101 & 39.15 & 48.05 & 0.36 & 11.37 & \\
\hline & TCU109 & 535.13 & 0.15941 & 57.11 & 37.649 & 0.37 & 13.06 & \\
\hline & TCU087 & 538.69 & 0.11697 & 42.41 & 51.865 & 0.37 & 6.98 & \\
\hline & TCU050 & 542.41 & 0.14417 & 37.233 & 46.979 & 0.26 & 9.49 & \\
\hline & TCU048 & 551.21 & 0.13435 & 42.379 & 51.429 & 0.32 & 13.53 & \\
\hline & TCU057 & 555.23 & 0.11363 & 39.208 & 51.227 & 0.35 & 11.83 & \\
\hline & TCU075 & 573.02 & 0.30134 & 79.037 & 70.594 & 0.27 & 0.89 & \\
\hline & TCU052 & 579.1 & 0.39658 & 116.56 & 221.2 & 0.43 & 0.3 & \\
\hline & TCU128 & 599.64 & 0.16034 & 63.283 & 63.457 & 0.40 & 13.13 & \\
\hline & TCU102 & 714.27 & 0.26678 & 80.098 & 75.329 & 0.31 & 1.49 & \\
\hline
\end{tabular}

TABLE 2: Variation of site factors and periods for Chi-Chi earthquake under different ground sites.

\begin{tabular}{lccccccc}
\hline Site & $V_{s}(\mathrm{~m} / \mathrm{s})$ & $T_{B}(\mathrm{~s})$ & $T_{\mathrm{C}}(\mathrm{s})$ & $T_{D}(\mathrm{~s})$ & $S(\mathrm{~s})$ & $\alpha$ & $\beta$ \\
\hline Hard & $>530$ & 0.28 & 0.66 & 4.60 & 1.09 & 0.55 & 0.70 \\
Medium & $390-530$ & 0.40 & 0.96 & 5.80 & 1.13 & 0.82 & 0.20 \\
Soft & $<390$ & 0.60 & 1.60 & 6.40 & 1.16 & 1.10 & 1.00
\end{tabular}

As shown in Table 1, the selected seismic records are classified into three categories, which are hard, medium, and soft soil site, respectively. The lower and upper limits for each parameter of different site are listed in Table 2. During the establishment of the design elastic spectrum, the PGA is adjusted to $0.3 \mathrm{~g}$. The elastic design spectrum is obtained by fitting the average response spectrum curve. According to these considerations, the design response spectrum for ChiChi earthquake is shown in Figure 2. It can be seen from the figures that the proposed design spectra are conservative compared to the average spectrum. Owing to the long duration pulses, the corner periods are larger than that the Eurocode 8 recommends.

2.2. Artificial Earthquakes for Different Ground Sites. Based on the above discussions, three artificial earthquakes that are characterized by Chi-Chi near-fault earthquakes under different ground sites are generated by power spectral density function, as shown in Figure 3. The artificial earthquakes are calculated with a time step of $0.01 \mathrm{~s}$ and the PGA is equal to $0.3 \mathrm{~g}$. Artificial earthquakes for hard, medium, and soft soil site are shown in Figures 4-6, respectively. From these figures, it can be observed that the velocity time histories of the generated artificial earthquakes possess obvious pulses with peak velocities. Owing to the similar design spectrum, the time histories of the generated artificial for hard site and medium site are the same despite several nuances. However, 


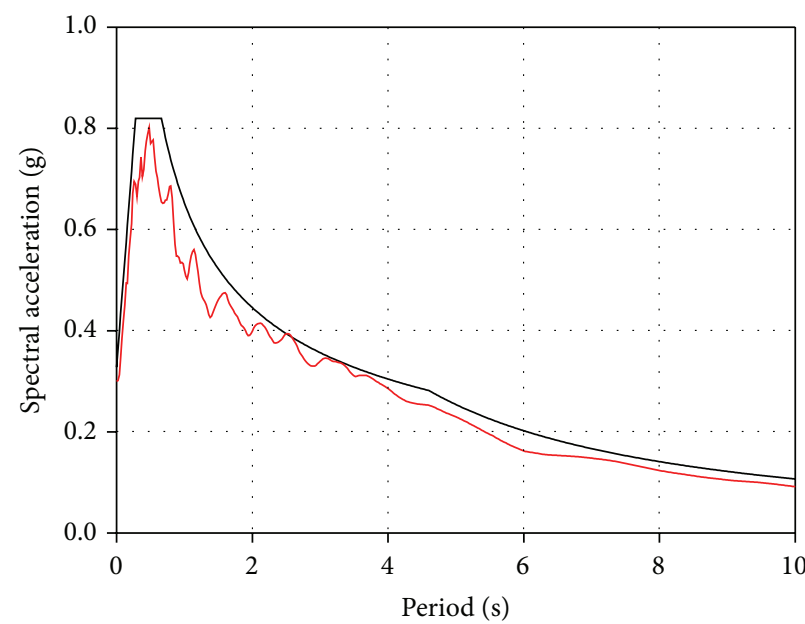

Design acceleration spectrum Mean spectrum

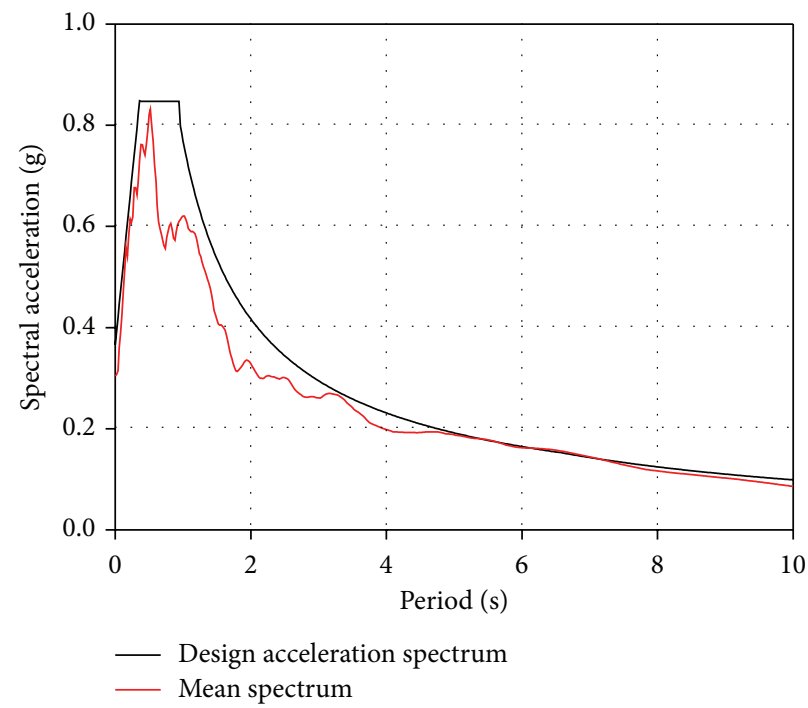

(b) Medium soil site

(a) Hard soil site

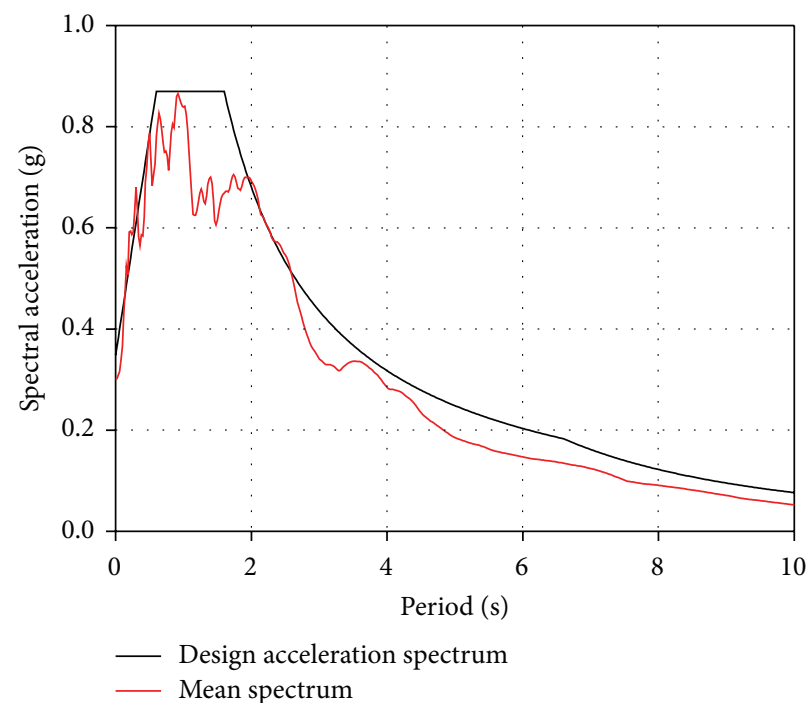

(c) Soft soil site

FIGURE 2: Design spectrum envelopes for Chi-Chi earthquake.

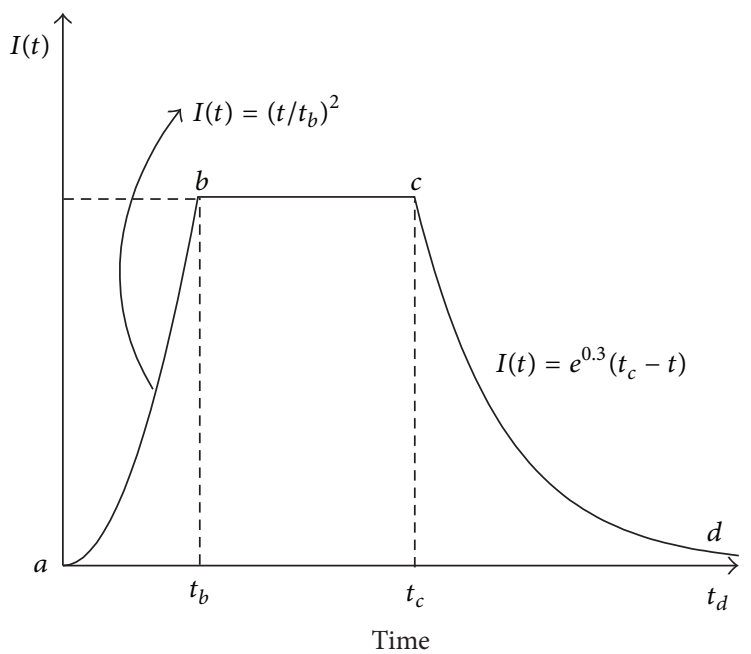

FIgURE 3: Envelop for artificial earthquake. 


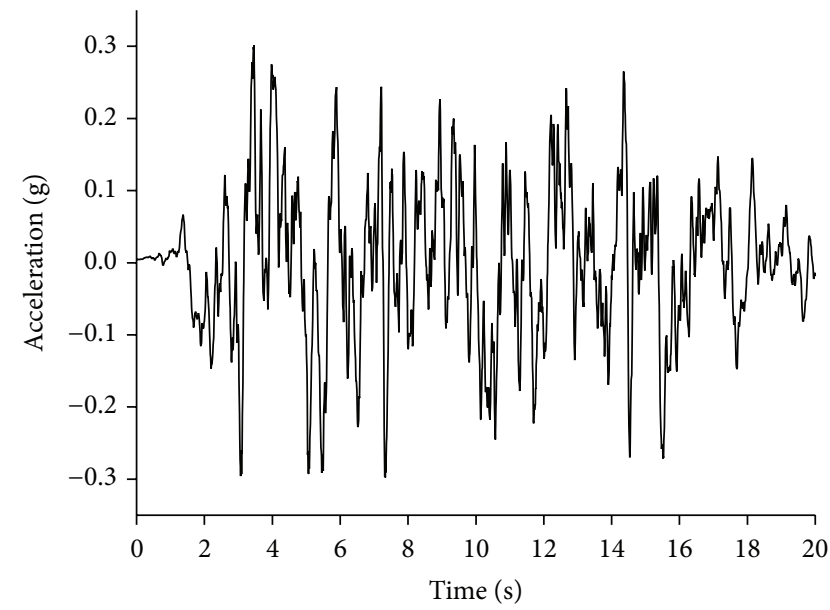

(a) Time history of acceleration

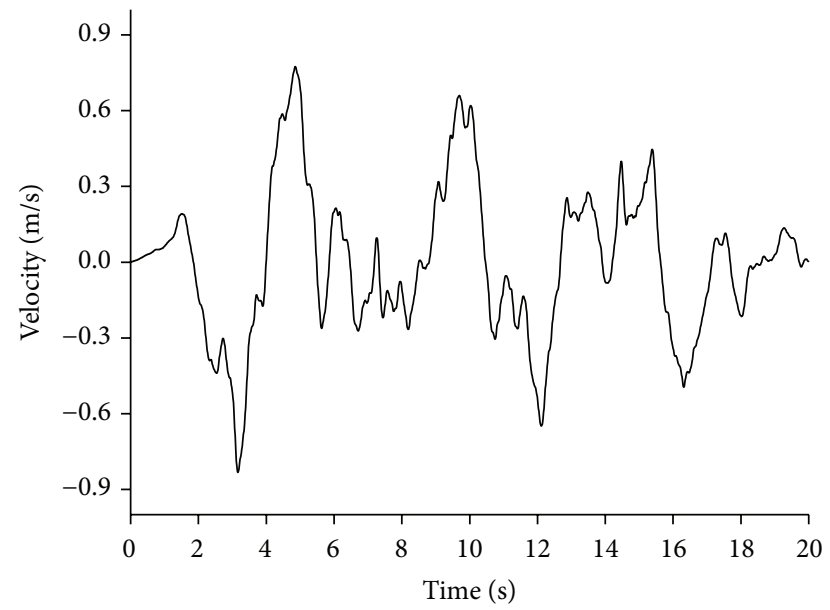

(b) Time history of velocity

FIGURE 4: Artificial earthquakes for hard soil site.

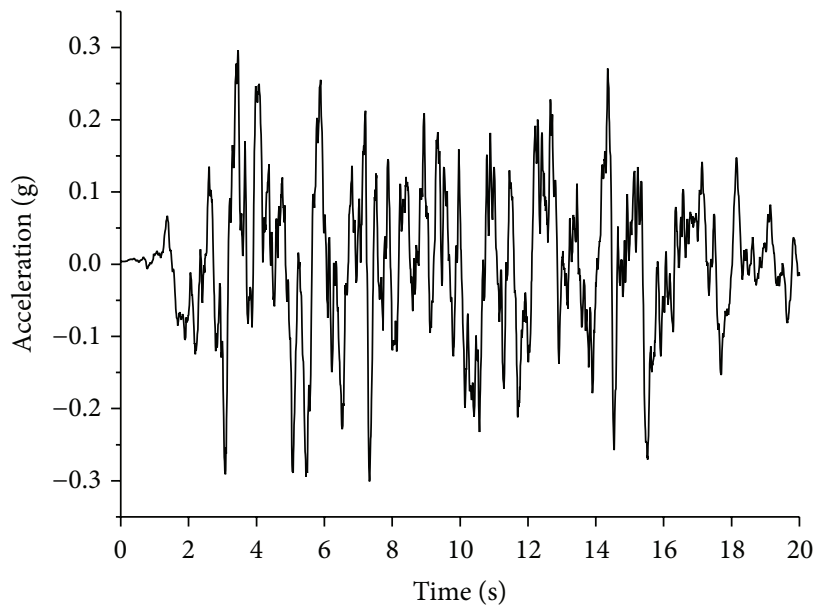

(a) Time history of acceleration

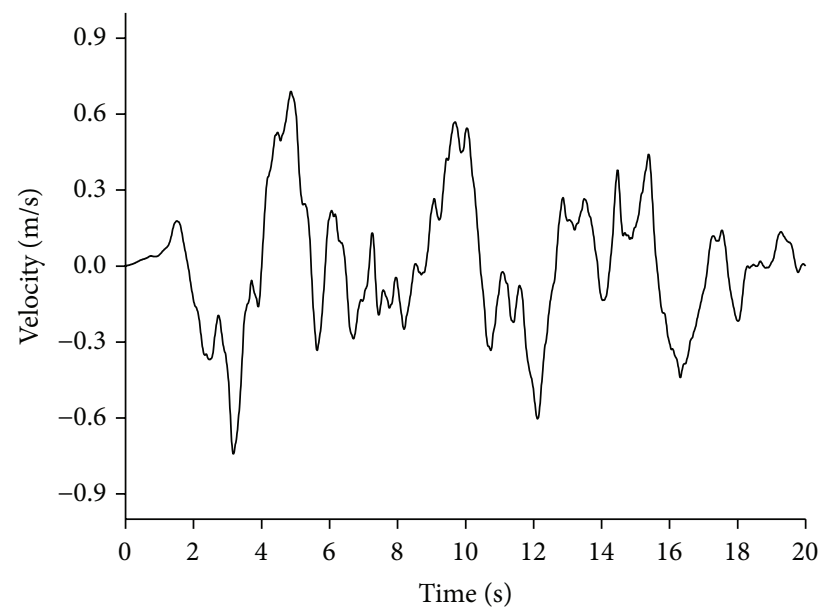

(b) Time history of velocity

FIgURE 5: Artificial earthquake for medium soil site.

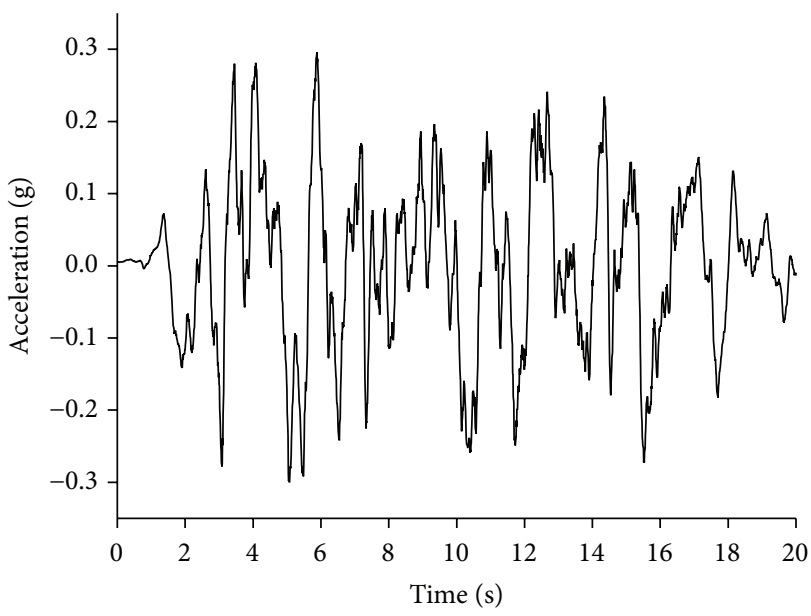

(a) Time history of acceleration

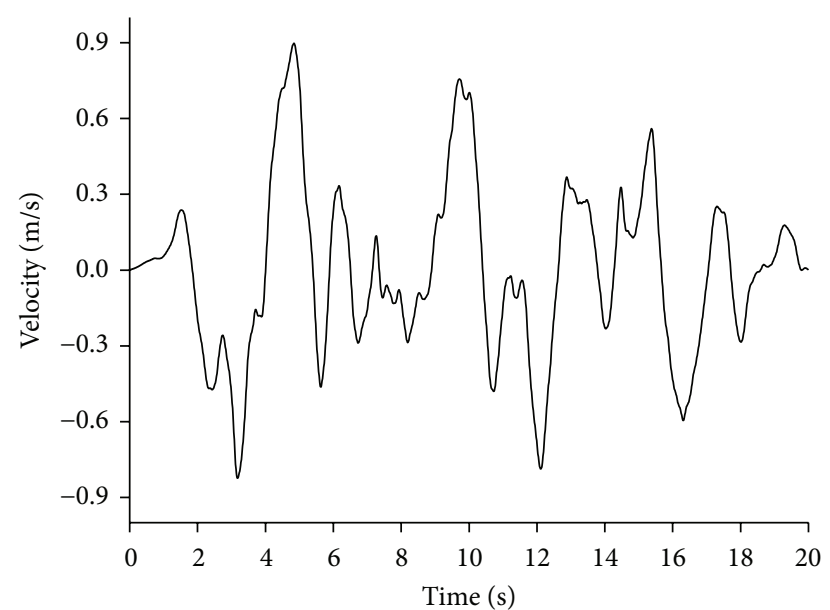

(b) Time history of velocity

Figure 6: Artificial earthquake for soft soil site. 
the time history of the generated artificial earthquakes for soft soil is distinct with the other. Particularly, the peak velocity reaches $0.9 \mathrm{~m} / \mathrm{s}$, which is significantly greater than the other.

\section{Model of Base-Isolated Structure and Piezoelectric Friction Damper}

3.1. Equation of Motion for Base-Isolated Structure. Consider an $n$-degree of freedom base-isolated structure with a piezoelectric friction damper at the isolation floor, the dynamic equation of the base-isolated system is given by

$$
\mathbf{M} \ddot{\mathbf{X}}(t)+\mathbf{C} \dot{\mathbf{X}}(t)+\mathbf{K X}(t)=\mathbf{B}_{s} \mathbf{U}(t)+\mathbf{E}_{s} \ddot{X}_{g}(t),
$$

where $\mathbf{M}, \mathbf{C}$, and $\mathbf{K}$ represent $n \times n$ mass, damping, and stiffness matrices, respectively; $\ddot{\mathbf{X}}(t), \dot{\mathbf{X}}(t)$, and $\mathbf{X}(t)$ are the acceleration, velocity, and displacement vectors, respectively; $\mathbf{U}(t)$ is the control force generated by the piezoelectric friction damper; and $\ddot{X}_{g}(t)$ is the earthquake acceleration.

Rewriting (2) in state-space form gives

$$
\dot{\mathbf{Z}}(t)=\mathbf{A Z}(t)+\mathbf{B U}(t)+\mathbf{E} \ddot{X}_{g}(t),
$$

where

$$
\begin{aligned}
\mathbf{Z}(t) & =\left[\begin{array}{c}
\mathbf{X}(t) \\
\dot{\mathbf{X}}(t)
\end{array}\right], \\
\mathbf{E} & =\left[\begin{array}{c}
\mathbf{0}_{n \times 1} \\
\mathbf{M}^{-1} \mathbf{E}_{s}
\end{array}\right], \\
\mathbf{B} & =\left[\begin{array}{c}
\mathbf{0}_{n \times 1} \\
\mathbf{M}^{-1} \mathbf{B}_{s}
\end{array}\right], \\
\mathbf{A} & =\left[\begin{array}{cc}
\mathbf{0}_{n \times n} & \mathbf{I}_{n \times n} \\
-\mathbf{M}^{-1} \mathbf{K} & -\mathbf{M}^{-1} \mathbf{C}
\end{array}\right] .
\end{aligned}
$$

3.2. Model of Piezoelectric Friction Damper. Piezoelectric friction damper is a novel semiactive control device, which utilizes piezoelectric stacks to regulate the damping force to provide a satisfying level of friction force. Recently, the authors also proposed a piezoelectric friction damper and investigated their performances theoretically and experimentally [17].

During the movement of the base-isolated structure, a friction damper has two possible motion states, sticking and slipping phases $[18,19]$. The friction force of the piezoelectric friction damper is given as [20]

$$
\begin{aligned}
N(t) & =N_{\text {pre }}+C_{\mathrm{pz}} V(t), \\
f(t) & =-\mu N(t) \operatorname{sgn}(\dot{x}), \quad \dot{x} \neq 0, \\
-\mu N(t) & \leq f(t) \leq \mu N(t), \quad \dot{x}=0,
\end{aligned}
$$

where $N(t)$ is the total contact force, $N_{\text {pre }}$ represents the preload of the piezoelectric friction damper, $C_{\mathrm{pz}}$ is the piezoelectric coefficient of the piezoelectric actuator, $V(t)$ is the input voltage of piezoelectric stack actuator, $\mu$ is the
TABLE 3: Parameters of piezoelectric friction damper.

\begin{tabular}{lc}
\hline Parameters & Values \\
\hline$\mu$ & 0.4 \\
$C_{\mathrm{pz}}$ & $1.125 \mathrm{~N} / \mathrm{V}$ \\
$V_{\max }$ & $1000 \mathrm{~V}$ \\
\hline
\end{tabular}

friction coefficient of the damper, $\operatorname{sgn}(\cdot)$ represents the sign function related to the slip rate of the damper, and $f(t)$ denotes damping force of piezoelectric friction damper.

However, the static state of the piezoelectric friction damper is complex to be estimated. Shook et al. [21] proposed an approximate calculation formula for the sticking friction force, as given in the following:

$$
\begin{aligned}
& f_{s}=-\mu N(t) \operatorname{sgn}(\dot{x}) \\
& \text { when } f_{s}=\left|f_{i}+f_{r}\right|,|f(t)| \geq f_{s}, \\
& f_{i}=m_{t} \ddot{x}_{g}=\left(m_{b}+\sum_{i=1}^{n} m_{i}\right) \ddot{x}_{g}, \\
& f_{r}=k_{b} x_{b},
\end{aligned}
$$

where $f_{i}$ is the inertial force applied on the mass, $f_{r}$ is the restoring force provided by the isolation bearing, $m_{i}$ is the mass of the superstructure, $m_{b}$ and $k_{b}$ are the mass and stiffness of base isolator, and $x_{b}$ is the displacement of base isolator.

The parameters of piezoelectric friction damper are listed in Table 3. And, the preload of the piezoelectric friction damper can be optimized by genetic algorithm.

\section{GA-Based Hierarchic Fuzzy Control Algorithm}

4.1. Framework of the Developed Fuzzy Logic Controller. The controller adopts a hierarchic fuzzy control algorithm in which a supervisory fuzzy controller governs a sublevel fuzzy controller by altering its input normalization factors according to the current level of ground motion. The sublevel fuzzy logic controller is designed to determine the command voltage of piezoelectric friction damper according to the velocity and displacement of base isolation. Piezoelectric friction damper regulates the damping force according to the input voltage. Genetic algorithm is employed to optimize supervisory fuzzy controller and preload of piezoelectric friction damper according to an objective function and the generated artificial earthquakes for different ground sites. The block diagram of the system for the developed controller is shown in Figure 7.

4.2. Sublevel Fuzzy Controller. The sublevel fuzzy controller is established in order to determine the command voltage of the piezoelectric friction damper. The isolation displacement and velocity are selected as two input variables, and command voltage is employed as a single output variable, as shown in Figure 8 . The definitions of the membership function of input 


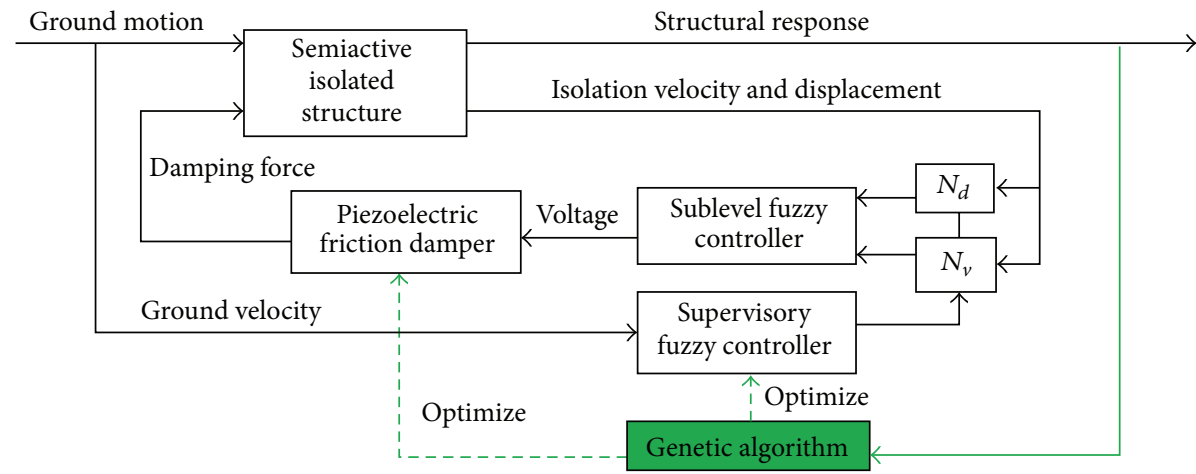

FIGURE 7: Block diagram of the base-isolated system for the fuzzy controller.
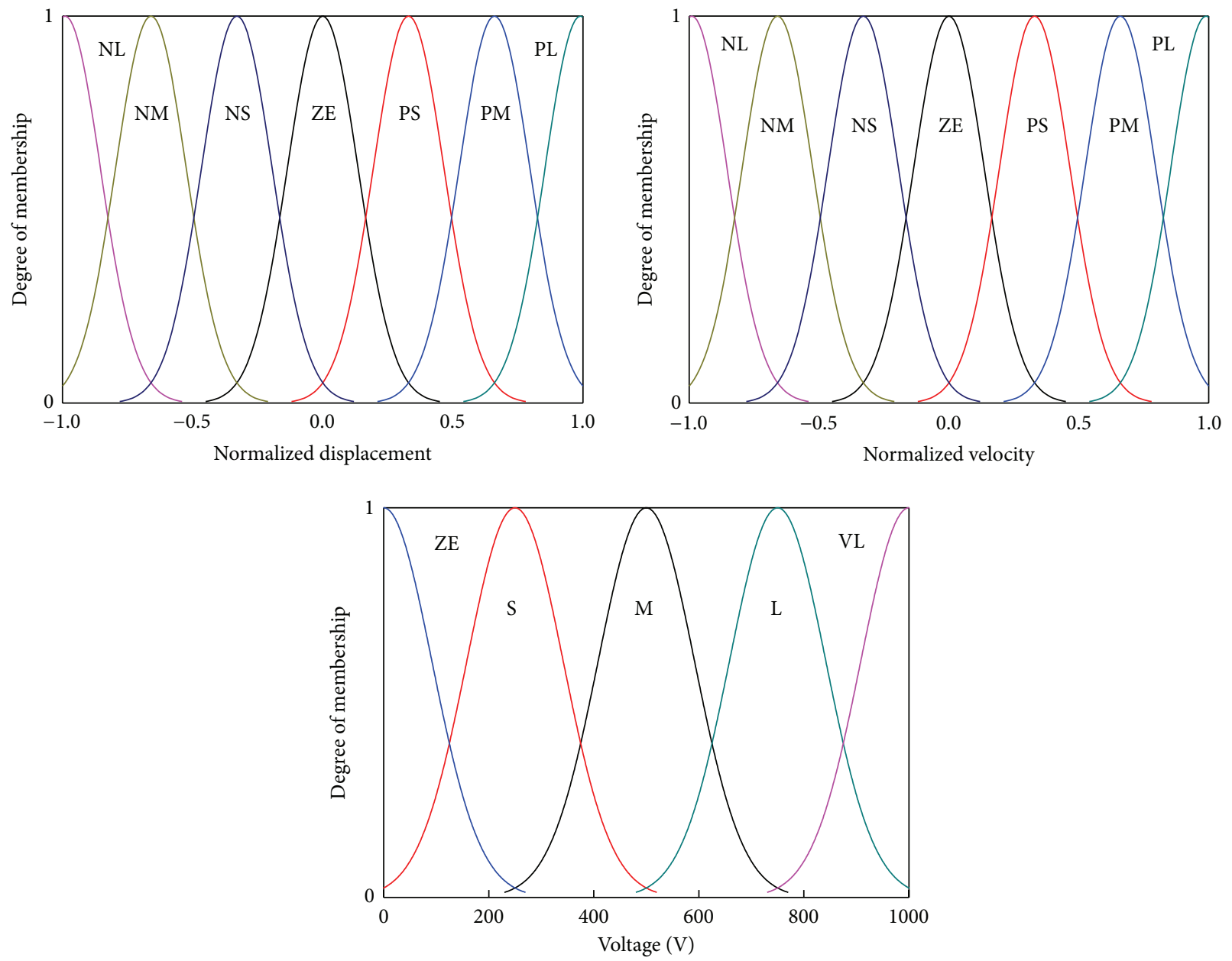

FIGURE 8: Input and output membership functions of sublevel fuzzy control.

variables are as follows: NL: negative large; NM: negative medium; NS: negative small; ZE: zero; PS: positive small; PM: positive medium; and PL: positive large. The definition of the membership function of output variable is as follows: $\mathrm{ZE}$ : zero; S: small; M: medium; L: large; and VL: very large. The membership functions are employed Gaussian type for input and output variables. The fuzzy control rules are defined in Table 4 .
In the establishment of fuzzy control rules, it follows the following principles: if the isolation displacement and velocity are in opposite sign, then the output voltage becomes small in order to ensure output small damping force in the piezoelectric friction damper. Contrarily, if the isolation displacement and velocity have the same sign, the output voltage becomes large. Certainly, when the displacement and velocity are almost zero or small, the command voltage is 
TABLE 4: Fuzzy control rules adopted for sublevel fuzzy control.

\begin{tabular}{lccccccc}
\hline Velocity of & \multicolumn{7}{c}{ Displacement of isolated floor } \\
isolated floor & NL & NM & NS & ZE & PS & PM & PL \\
\hline NL & VL & VL & L & L & M & S & ZE \\
NM & VL & L & L & M & S & ZE & S \\
NS & L & L & M & S & ZE & S & M \\
ZE & L & M & S & ZE & S & M & L \\
PS & M & S & ZE & S & M & L & L \\
PM & S & ZE & S & M & L & L & VL \\
PL & ZE & S & M & L & L & VL & VL \\
\hline
\end{tabular}

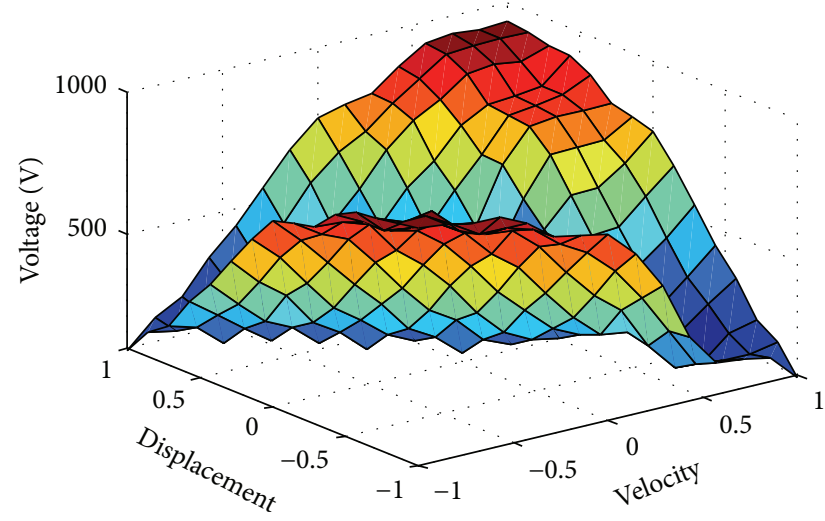

FIGURE 9: Fuzzy control surface for sublevel fuzzy controller.

about zero; this means that piezoelectric friction damper acts as a passive friction damper. The defuzzification of fuzzy control adopts the method of centroid to get a crisp output value. The control surface and color-filled contour line of sublevel fuzzy control are depicted in Figure 9.

4.3. Supervisory Fuzzy Logic Controller. In the fuzzy logic control, normalization factors need to satisfy a certain objective. The oversize normalization factors can enlarge the base displacement effectively. Contrarily, too small normalization factors can result in large control force that amplifies the accelerations of base-isolated structure. Thus, a supervisory fuzzy logic control is proposed to adjust its normalization factors in real-time. As discussed earlier, near-fault earthquakes usually have long duration pulses with peak velocities. Thus, the supervisory fuzzy control employs ground velocity as single input variable to identify the characteristics of the ground motion. The normalization factors of sublevel fuzzy control are selected as two output variables. Here, Gaussian membership functions are used for input and output variables, as shown in

$$
\mu_{\text {gauss }}=\exp \left[-\frac{(x-c)^{2}}{2 \sigma^{2}}\right]
$$

where $c$ and $\sigma$ are the constant values that define the shape of the Gauss functions, respectively.
The rules of the supervisory fuzzy controller are defined by the following form:

$$
\begin{aligned}
& \text { Rule }^{i} \text { : IF } X \text { is } A^{i} \text {, then } Y_{1} \text { is } C_{1}^{i}, Y_{2} \text { is } C_{2}^{i} \text {, } \\
& i=1,2, \ldots, M,
\end{aligned}
$$

where $M$ is the number of fuzzy control rules, $X$ is the input variable, $Y_{1}$ and $Y_{2}$ are the output variables, $A^{i} C_{1}^{i}$, and $C_{2}^{i}$ are the linguistic values characterized by input and output membership functions, respectively. One fuzzy control rule is described by three Gaussian membership functions, and each membership function can be defined by two parameters $(c$ and $\sigma)$. Therefore, a total of five fuzzy control rules can be optimized by encoding these two parameters into the gene using genetic algorithm. Consequently, a total of 30 parameters are encoded into the chromosome to define the inference system of supervisory fuzzy controller, as shown in Figure 10.

Similar to normalization factors, the preload of the piezoelectric friction dampers has a great influence on the damping effect. Thus, it is essential to establish an effective supervisory fuzzy logic controller and a suitable preload of piezoelectric friction damper. Generally, for the seismic protection of a base-isolated structure, there is a tradeoff between the isolation displacement and superstructure acceleration. The main control objective is to depress the isolation displacement without excessively increasing acceleration response of the superstructure. In this section, a genetic algorithm is employed to seek out an optimal solution for the control of the base-isolated structure. The flow chart of genetic algorithm is shown in Figure 11.

Genetic algorithm is a computational model for the simulation of Darwin natural genetic selection and biological evolution. Different from the traditional search algorithm, genetic algorithm begins to search a group of optimal solutions from an initial random population by mutation and recombination. Each individual, which consists of a set of binary strings, is a solution to the objective problem. After initialization, genetic algorithm uses a sort method to rank individuals. It compares each solution with other solutions in the population to find whether it is dominated. During the process of creating a new generation, it selects a suitable individual according to the size of the fitness value. After several generations, the individual value gradually converges to the best chromosome, which is the optimal solution.

The objective fitness function employed in this study is shown as follows:

$$
J=0.6 \times \frac{\widehat{y}_{b, \max }}{y_{b, \max }}+0.4 \times \sqrt{\frac{\sum_{i=1}^{n}\left(\widehat{a}_{i, \max } / a_{i, \max }\right)^{2}}{n}},
$$

where $\hat{y}_{b, \text { max }}$ and $y_{b, \text { max }}$ denote the peak base displacements for the fuzzy control and uncontrolled cases, respectively; $\widehat{a}_{i, \max }$ and $a_{i, \max }$ represent the peak superstructure acceleration for the fuzzy control and uncontrolled case, respectively.

The objective of genetic algorithm is to make the objective fitness function reach its minimum value by selecting one set of parameters of supervisory fuzzy control and preload 

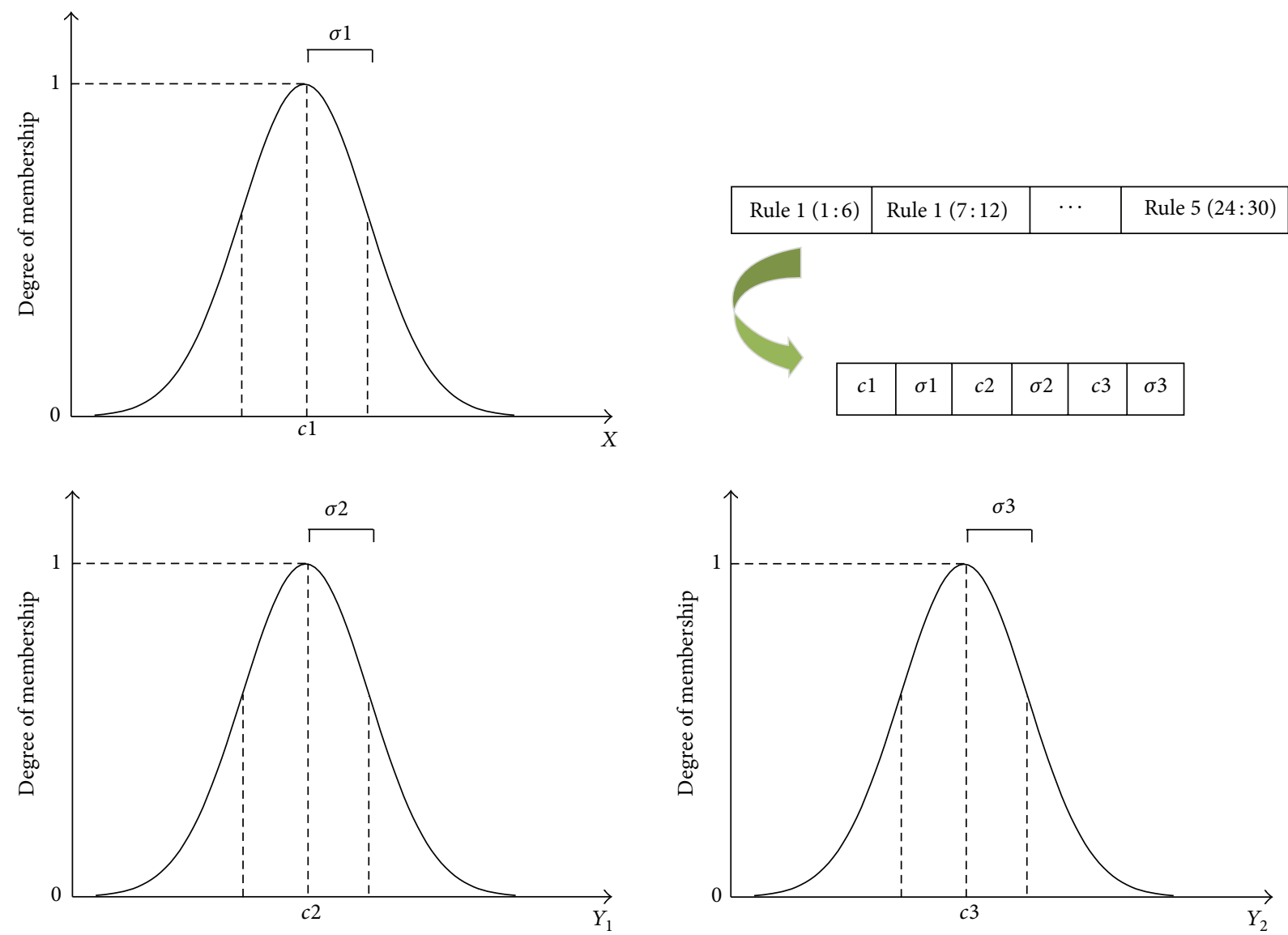

FIGURE 10: Encoding structure for genetic algorithm.

of piezoelectric friction damper. The initial population size, genetic algebra, and crossover probability are set to 20,50 , and 0.8 , respectively. Through inputting the artificial earthquakes which are characterized by near-fault earthquakes for different ground sites, the supervisory fuzzy control and preload of piezoelectric friction dampers can be optimized. The fuzzy control surfaces of optimized supervisory fuzzy control are shown in Figure 12.

\section{Linear Quadratic Gaussian Controller}

LQG (Linear Quadratic Gaussian) method is based on Kalman filter technique, which has become a widely used control algorithm. For comparison purpose, LQG is adopted to regulate the contact normal force of piezoelectric friction damper in the study. The optimal controller takes ground acceleration as white noise and considers the velocity and displacement of base isolation as feedback signals. The control performance index is defined as follows [22]:

$$
\begin{aligned}
J= & \lim _{\tau \rightarrow+\infty} \frac{1}{\tau} \\
& \cdot E\left\{\int_{0}^{\tau}\left[\mathbf{Z}(t)^{T} \mathbf{Q Z}(t)+\mathbf{U}(t)^{T} \mathbf{R} \mathbf{U}(t)\right] d(t)\right\},
\end{aligned}
$$

where $\mathbf{Q}_{2 n \times 2 n}$ and $\mathbf{R}_{1 \times 1}$ are semi-positive definite matrix and positive definite matrix, respectively. The control force can be obtained as follows:

$$
\begin{aligned}
\mathbf{U}(t) & =-\mathbf{G} \mathbf{Z}(t), \\
\mathbf{G} & =\mathbf{R}^{-1} \mathbf{B}^{T} \mathbf{P},
\end{aligned}
$$

where $\mathbf{P}$ can be computed by the solution of the Riccati equation as follows:

$$
-\mathbf{P A}-\mathbf{A}^{T} \mathbf{P}+\mathbf{P B R}^{-1} \mathbf{B}^{T} \mathbf{P}-\mathbf{Q}=\mathbf{0} .
$$

The control force obtained from the above equation is active control force, which could not be always achieved by piezoelectric friction damper. It is realized that the direction of active control force is opposite to the slipping direction of piezoelectric friction damper. Therefore, the desired control force $u_{d}(t)$ can be achieved according to the following criteria:

$$
\begin{aligned}
& u_{d}(t) \\
& = \begin{cases}f_{\max } \operatorname{sgn}\left(\dot{x}_{b}\right) & \left(u^{\text {active }} \dot{x}_{b}<0,\left|u^{\text {active }}\right|>f_{\max }\right), \\
\left|u^{\text {active }}\right| \operatorname{sgn}\left(\dot{x}_{b}\right) & \left(u^{\text {active }} \dot{x}_{b}<0,\left|u^{\text {active }}\right| \leq f_{\max }\right), \\
f_{\min } \operatorname{sgn}\left(\dot{x}_{b}\right) & \left(u^{\text {active }} \dot{x}_{b} \geq 0\right),\end{cases}
\end{aligned}
$$


TABLE 5: Parameters of base-isolated structure.

\begin{tabular}{lccc}
\hline & $\begin{array}{c}\text { Floor masses } \\
(\mathrm{kg})\end{array}$ & $\begin{array}{c}\text { Stiffness values } \\
(\mathrm{kN} / \mathrm{m})\end{array}$ & $\begin{array}{c}\text { Damping } \\
\text { coefficients } \\
(\mathrm{kN} \mathrm{s} / \mathrm{m})\end{array}$ \\
\hline Isolated floor & 6800 & 232 & 7.45 \\
First floor & 5897 & 33732 & 67 \\
Second floor & 5897 & 29093 & 58 \\
Third floor & 5897 & 28621 & 57 \\
Fourth floor & 5897 & 24954 & 50 \\
Fifth floor & 5897 & 19059 & 38 \\
\hline
\end{tabular}

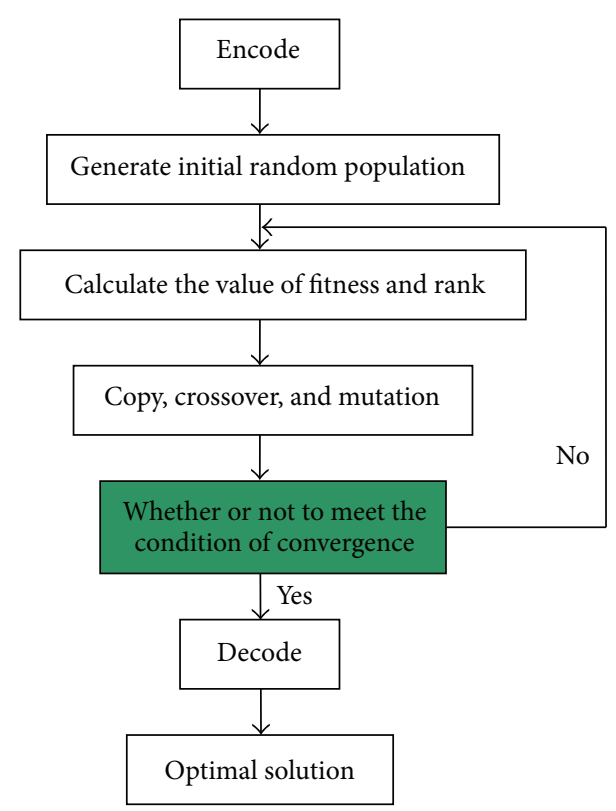

FIGURE 11: Flow chart of genetic algorithm.

where $u^{\text {active }}$ is the control force obtained from LQG controller; $\dot{x}_{b}$ is the velocity of base isolator; $f_{\max }$ and $f_{\min }$ are the maximum and minimum friction forces of the piezoelectric friction damper, respectively.

\section{Numerical Simulations}

6.1. Model of the Base-Isolated Structure. A five-story baseisolated building, which is proposed by He et al., is employed to evaluate the performance of developed fuzzy controllers [18]. The fundamental period of the five-story building is $0.3 \mathrm{~s}$. For the given isolation parameters, the fundamental period of the base-isolated building becomes $2.5 \mathrm{~s}$. Therefore, an isolation ratio $\delta$ equal to $8.3(=2.5 / 0.3)$ is obtained. The model of the base-isolated structure with piezoelectric friction damper is shown in Figure 13. The parameters of the base-isolated structure are shown in Table 5 .

6.2. Performance Evaluation Index. In order to evaluate the performance of base-isolated structure for different control algorithms, a total of nine performance indexes are employed in this study [23], as shown in Table 6.
The performance indexes $J_{1}$ through $J_{5}$ denote the structure responses for the controlled building normalized by uncontrolled structure, respectively. The performance index $J_{6}$ evaluates the peak control force normalized by the peak base shear for controlled structure. The performance indexes $J_{7}$ and $J_{8}$ represent RMS (Root Mean Square) base displacements and RMS floor accelerations, respectively. $J_{9}$ computes the energy dissipated by friction dampers normalized by the earthquake input energy to the controlled structure.

6.3. Simulation Results and Analysis. A total of nine seismic excitations that contain six real ground motions and three artificial earthquakes are selected to evaluate the performance of the optimized fuzzy logic controller. In this study, the time histories of strong earthquake, which range from $20 \mathrm{~s}$ to $70 \mathrm{~s}$, are selected for numerical simulation and analysis.

The numerical results for various earthquakes are listed in Table 7. In the table, the Genetic Algorithm Hierarchic Fuzzy Logic Control is named as GHFLC. Moreover, for comparison purpose, the results for an optimal controller and passive operation of friction damper are also listed in the table. Numbers in bold font indicate the best results among all control cases.

Base displacement is an important index to evaluate the effectiveness for different controllers. For a base-isolated structure, the reduction of base displacement is a primary purpose to prevent permanent damage for isolation bearings or adjacent buildings. Although passive operation of friction dampers can successfully reduce the performance index associated with the peak and RMS base displacements $\left(J_{3}\right.$ and $J_{7}$ ), it causes significant amplification in peak and RMS floor accelerations $\left(J_{5}\right.$ and $\left.J_{8}\right)$ for most cases due to the passive control. For example, as compared to the uncontrolled structure, for TCU052, TCU053, and TCU054 earthquakes, passive control leads to $6 \%, 45 \%$, and $42 \%$ amplification in peak floor acceleration, respectively. However, the proposed fuzzy controller can successfully improve the base-isolated structure acceleration at the cost of slight deterioration in the performance indices $J_{3}$ and $J_{7}$ on comparison with passive control. For example, for TCU052, TCU053, and TCU054 earthquakes, GHFLC results in $15 \%, 13 \%$, and $16 \%$ decrease in peak floor accelerations, respectively. As compared to passive control, there are $9 \%, 3 \%$, and $7 \%$ increase in peak base displacements.

The time histories of friction force and forcedisplacement curves of friction dampers for different controllers subjected to TCU052 earthquake are shown in Figure 14. From the figures, it can be seen that the passive control outputs lager damper force than GHFLC. Because the supervisory fuzzy control can alter input normalization factors of sublevel FLC according to the current level of ground motion, there are some serrations presented at the edge of the hysteretic curve of piezoelectric friction damper.

The comparison of the performance indexes $J_{3}, J_{7}, J_{5}$, and $J_{8}$ under different control cases is shown in Figures 15 and 16, respectively. From these figures, it can be seen that the fuzzy controller is more effective than passive and optimal 

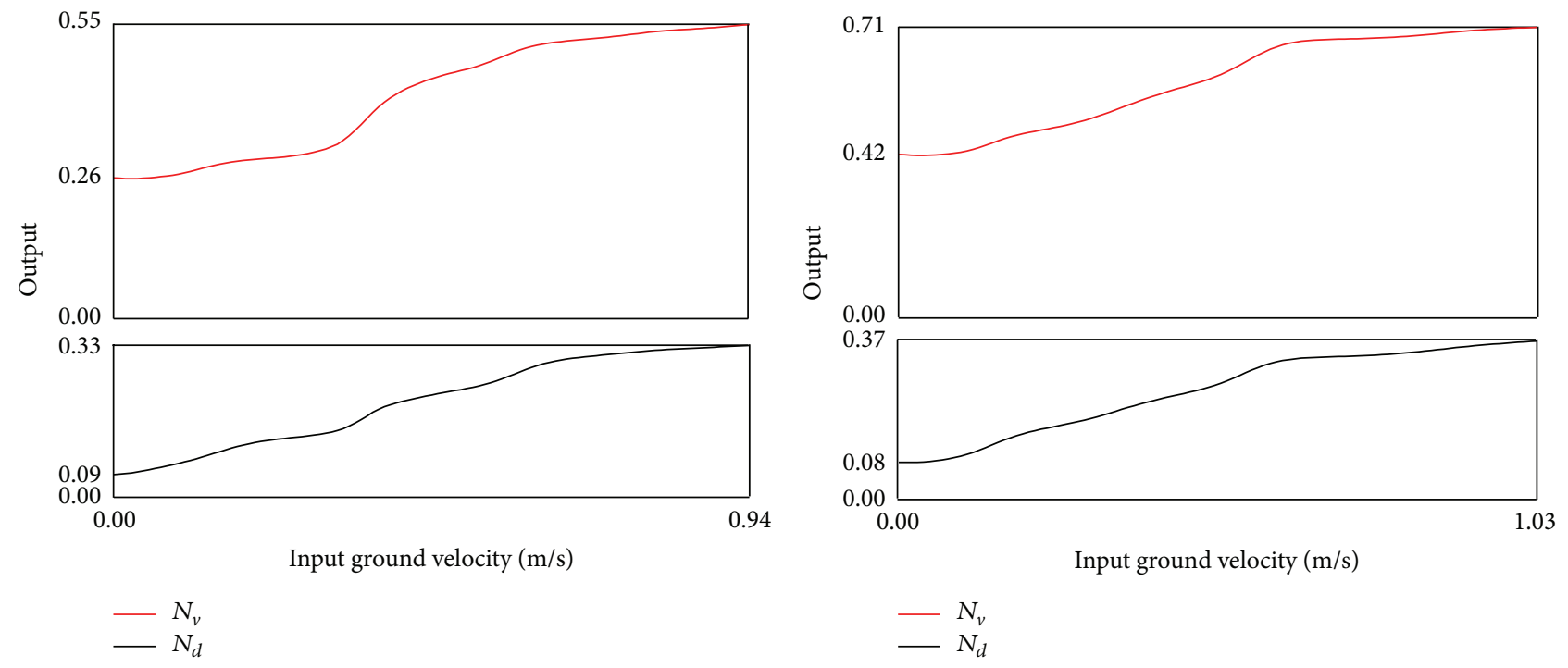

(a) Hard soil

(b) Medium soil

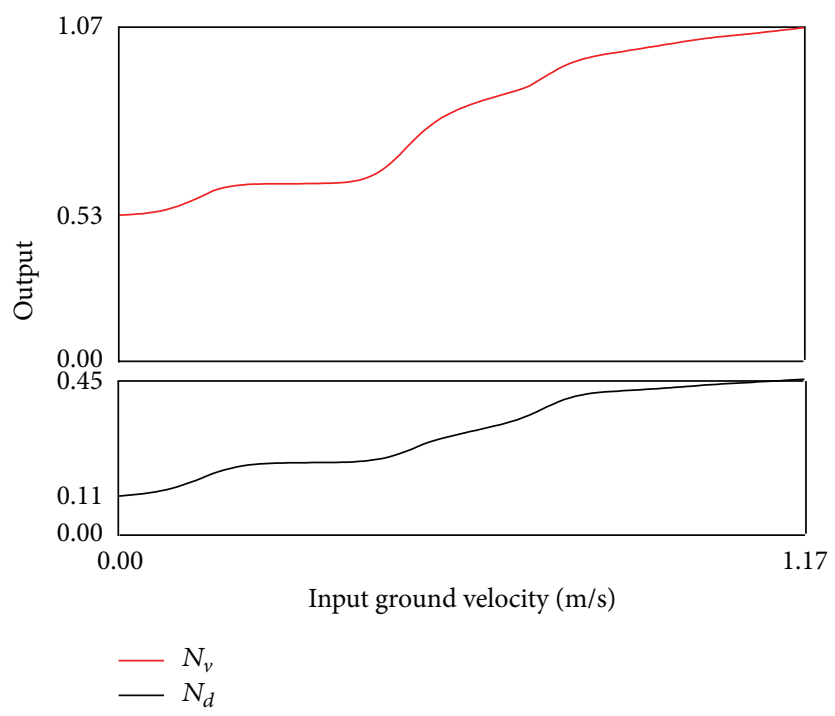

(c) Soft soil

FIgURE 12: Control surface for optimized supervisory fuzzy control.

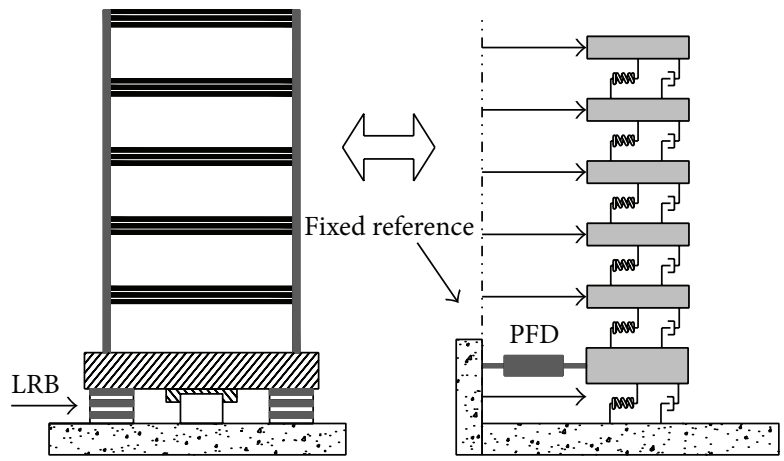

Figure 13: Model of the base-isolated structure. 
TABle 6: Performance index.

\begin{tabular}{lcr}
\hline Peak base shear & Peak interstory drift & RMS base displacement \\
$J_{1}=\frac{\max _{t}\left\|V_{0}(t)\right\|}{\max _{t}\left\|\widehat{V}_{0}(t)\right\|}$ & $J_{4}=\frac{\max _{t, f}\left\|d_{f}(t)\right\|}{\max _{t, f}\left\|\widehat{d}_{f}(t)\right\|}$ & $J_{7}=\frac{\max _{i}\left\|\sigma_{d}(t)\right\|}{\max _{t}\left\|\widehat{\sigma}_{d}(t)\right\|}$ \\
\hline Peak structural shear & Peak floor acceleration & RMS floor acceleration \\
$J_{2}=\frac{\max _{t}\left\|V_{1}(t)\right\|}{\max _{t}\left\|\widehat{V}_{1}(t)\right\|}$ & $J_{5}=\frac{\max _{t, f}\left\|a_{f}(t)\right\|}{\max _{t, f}\left\|\widehat{a}_{f}(t)\right\|} \| \frac{\max _{f}\left\|\sigma_{a}(t)\right\|}{\max _{f}\left\|\widehat{\sigma}_{a}(t)\right\|}$ \\
\hline Peak base displacement & Peak control force & Energy dissipated by PFD \\
$J_{3}=\frac{\max _{t}\left\|x_{b}(t)\right\|}{\max _{t}\left\|\widehat{x}_{b}(t)\right\|}$ & $J_{6}=\frac{\max _{t}\left\|f_{d}(t)\right\|}{\max _{t}\left\|V_{0}(t)\right\|}$ & $J_{0}^{T} f_{d}(t) \dot{x}_{b}(t) d t$ \\
\hline
\end{tabular}

TABLE 7: Results of numerical simulation.

\begin{tabular}{|c|c|c|c|c|c|c|c|c|c|c|}
\hline Earthquake & Control case & $J_{1}$ & $J_{2}$ & $J_{3}$ & $J_{4}$ & $J_{5}$ & $J_{6}$ & $J_{7}$ & $J_{8}$ & $J_{9}$ \\
\hline \multirow{3}{*}{$\begin{array}{l}\text { TCU102 } \\
\text { (hard site) }\end{array}$} & Passive & 0.81 & 0.82 & 0.68 & 0.85 & 0.94 & 0.48 & 0.57 & 0.82 & 0.78 \\
\hline & Optimal & 0.92 & 0.95 & 0.75 & 0.99 & 0.87 & 0.43 & 0.68 & 0.81 & 0.69 \\
\hline & GHFLC & 0.87 & 0.91 & 0.71 & 0.93 & 0.82 & 0.41 & 0.61 & 0.78 & 0.73 \\
\hline \multirow{3}{*}{$\begin{array}{l}\text { TCU052 } \\
\text { (hard site) }\end{array}$} & Passive & 0.79 & 0.79 & 0.46 & 0.82 & 1.06 & 0.36 & 0.38 & 0.89 & 0.87 \\
\hline & Optimal & 0.87 & 0.87 & 0.57 & 0.87 & 0.98 & 0.29 & 0.49 & 0.85 & 0.79 \\
\hline & GHFLC & 0.83 & 0.82 & 0.55 & 0.82 & 0.91 & 0.33 & 0.44 & 0.79 & 0.84 \\
\hline \multirow{3}{*}{$\begin{array}{l}\text { Artificial } \\
\text { earthquake } \\
\text { (hard site) }\end{array}$} & Passive & 0.72 & 0.74 & 0.54 & 0.76 & 0.92 & 0.54 & 0.49 & 0.90 & 0.84 \\
\hline & Optimal & 0.84 & 0.86 & 0.69 & 0.83 & 0.89 & 0.47 & 0.57 & 0.86 & 0.73 \\
\hline & GHFLC & 0.76 & 0.77 & 0.61 & 0.79 & 0.83 & 0.42 & 0.52 & 0.81 & 0.76 \\
\hline \multirow{3}{*}{$\begin{array}{l}\text { TCU053 } \\
\text { (medium site) }\end{array}$} & Passive & 0.61 & 0.65 & 0.39 & 0.71 & 1.45 & 0.32 & 0.37 & 1.16 & 0.89 \\
\hline & Optimal & 0.69 & 0.72 & 0.46 & 0.76 & 1.36 & 0.31 & 0.45 & 1.17 & 0.78 \\
\hline & GHFLC & 0.62 & 0.62 & 0.42 & 0.65 & 1.32 & 0.26 & 0.44 & 1.09 & 0.72 \\
\hline \multirow{3}{*}{$\begin{array}{l}\text { TCU054 } \\
\text { (medium site) }\end{array}$} & Passive & 0.71 & 0.73 & 0.43 & 0.73 & 1.42 & 0.84 & 0.38 & 1.21 & 0.88 \\
\hline & Optimal & 0.81 & 0.87 & 0.45 & 0.85 & 1.32 & 0.79 & 0.52 & 1.25 & 0.86 \\
\hline & GHFLC & 0.75 & 0.71 & 0.40 & 0.74 & 1.26 & 0.82 & 0.45 & 1.13 & 0.76 \\
\hline \multirow{3}{*}{$\begin{array}{l}\text { Artificial } \\
\text { earthquake } \\
\text { (medium site) }\end{array}$} & Passive & 0.54 & 0.57 & 0.38 & 0.64 & 1.23 & 0.67 & 0.36 & 1.17 & 0.91 \\
\hline & Optimal & 0.67 & 0.66 & 0.47 & 0.67 & 1.19 & 0.78 & 0.48 & 1.13 & 0.79 \\
\hline & GHFLC & 0.58 & 0.61 & 0.40 & 0.62 & 1.13 & 0.72 & 0.41 & 1.09 & 0.85 \\
\hline \multirow{3}{*}{$\begin{array}{l}\text { TCU110 } \\
\text { (soft soil site) }\end{array}$} & Passive & 0.77 & 0.78 & 0.47 & 0.77 & 1.03 & 0.50 & 0.45 & 0.89 & 0.95 \\
\hline & Optimal & 0.83 & 0.82 & 0.52 & 0.85 & 1.07 & 0.46 & 0.52 & 0.99 & 0.87 \\
\hline & GHFLC & 0.86 & 0.86 & 0.56 & 0.86 & 1.04 & 0.42 & 0.49 & 0.93 & 0.90 \\
\hline \multirow{3}{*}{$\begin{array}{l}\text { CHY101 } \\
\text { (soft soil site) }\end{array}$} & Passive & 0.69 & 0.71 & 0.58 & 0.75 & 0.86 & 0.66 & 0.54 & 0.92 & 0.84 \\
\hline & Optimal & 0.75 & 0.73 & 0.62 & 0.74 & 0.87 & 0.64 & 0.55 & 0.88 & 0.79 \\
\hline & GHFLC & 0.63 & 0.67 & 0.54 & 0.67 & 0.79 & 0.65 & 0.51 & 0.87 & 0.83 \\
\hline \multirow{3}{*}{$\begin{array}{l}\text { Artificial } \\
\text { earthquake } \\
\text { (soft site) }\end{array}$} & Passive & 0.57 & 0.64 & 0.61 & 0.68 & 0.97 & 0.61 & 0.58 & 0.98 & 0.88 \\
\hline & Optimal & 0.71 & 0.70 & 0.74 & 0.75 & 0.94 & 0.58 & 0.71 & 0.93 & 0.83 \\
\hline & GHFLC & 0.65 & 0.62 & 0.67 & 0.69 & 0.85 & 0.55 & 0.63 & 0.86 & 0.76 \\
\hline
\end{tabular}

controller in simultaneously depressing the superstructure acceleration and base displacement. For example, the application of developed fuzzy controller leads to an average of $11.2 \%$ decrease in peak floor acceleration and an average of only $3.6 \%$ increase in peak base displacement as compared to passive control. Particularly, optimal controller produces an average of only $4.1 \%$ reduction in peak floor acceleration and leads to $7.9 \%$ increase in peak base displacement as compared to passive control. Therefore, the improved fuzzy control method shows better performance than passive and optimal control.

In order to further evaluate the performance of different controllers, the energy time histories for different controllers are compared with each other. For a base-isolated structure 

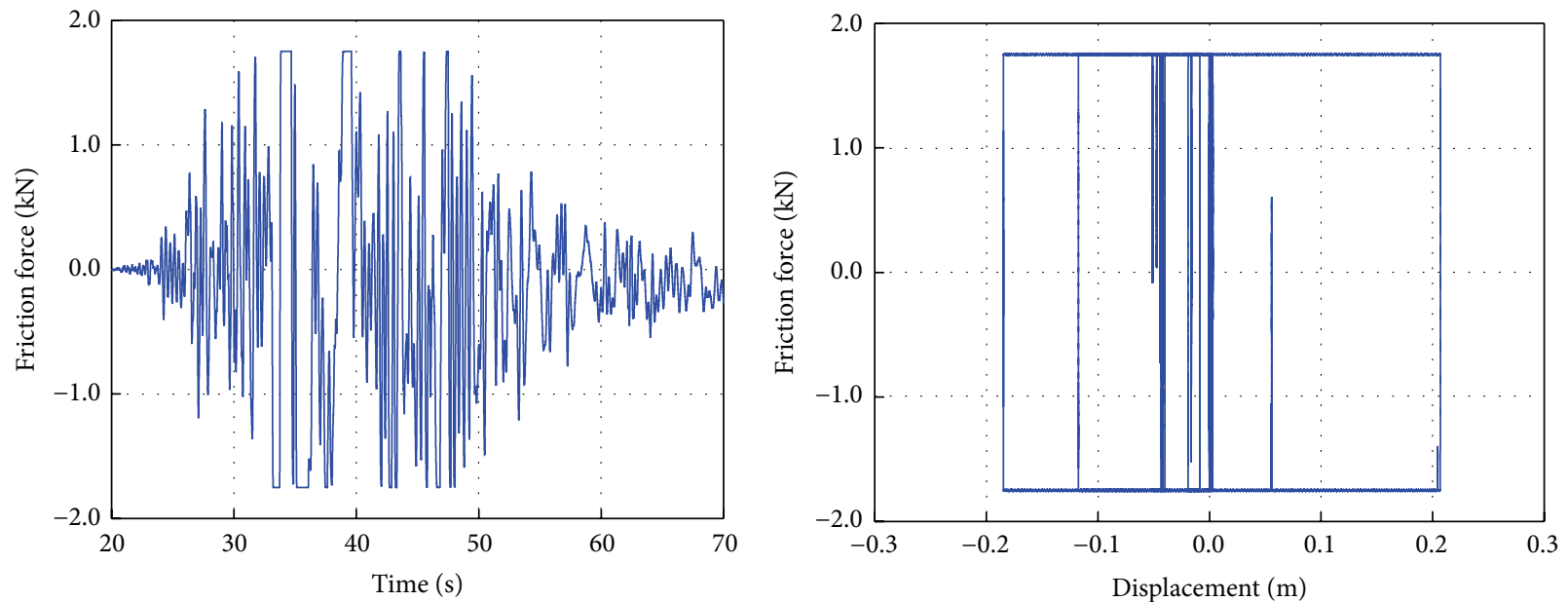

(a) Passive control
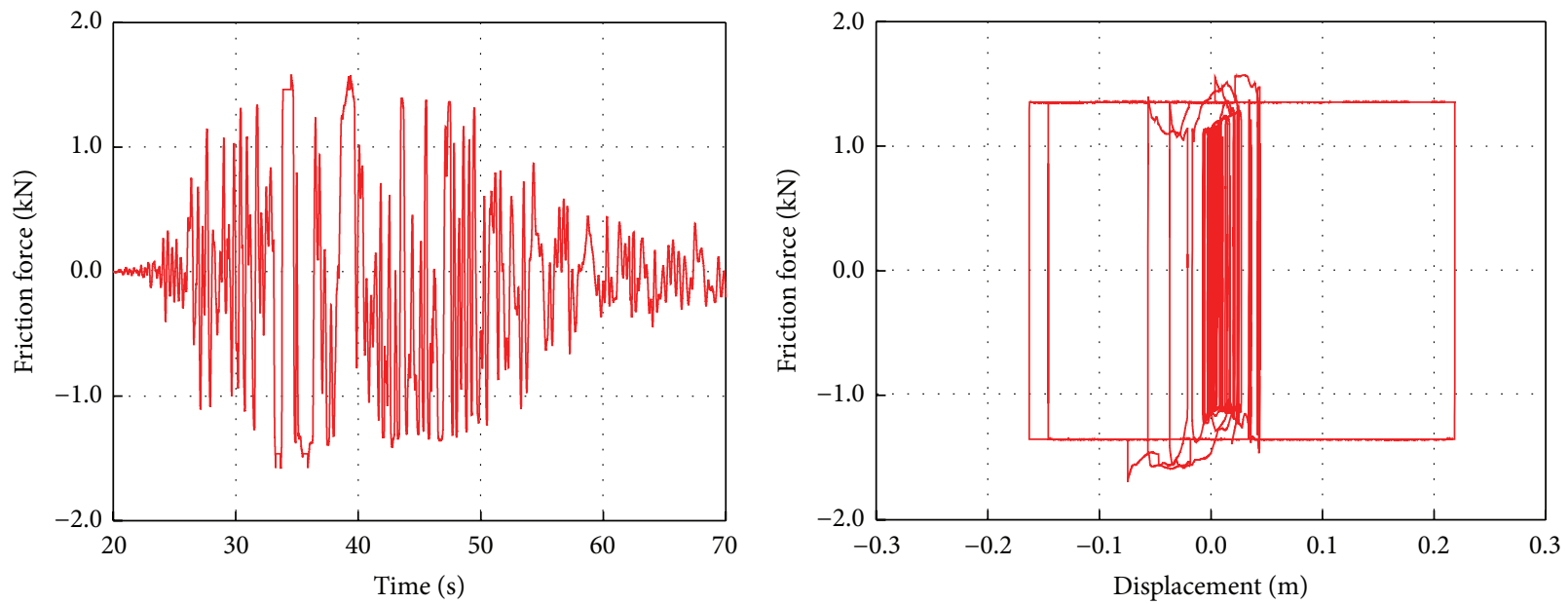

(b) GHFLC method

FIGURE 14: Time histories of friction force and force-displacement diagram against TCU052 earthquake.
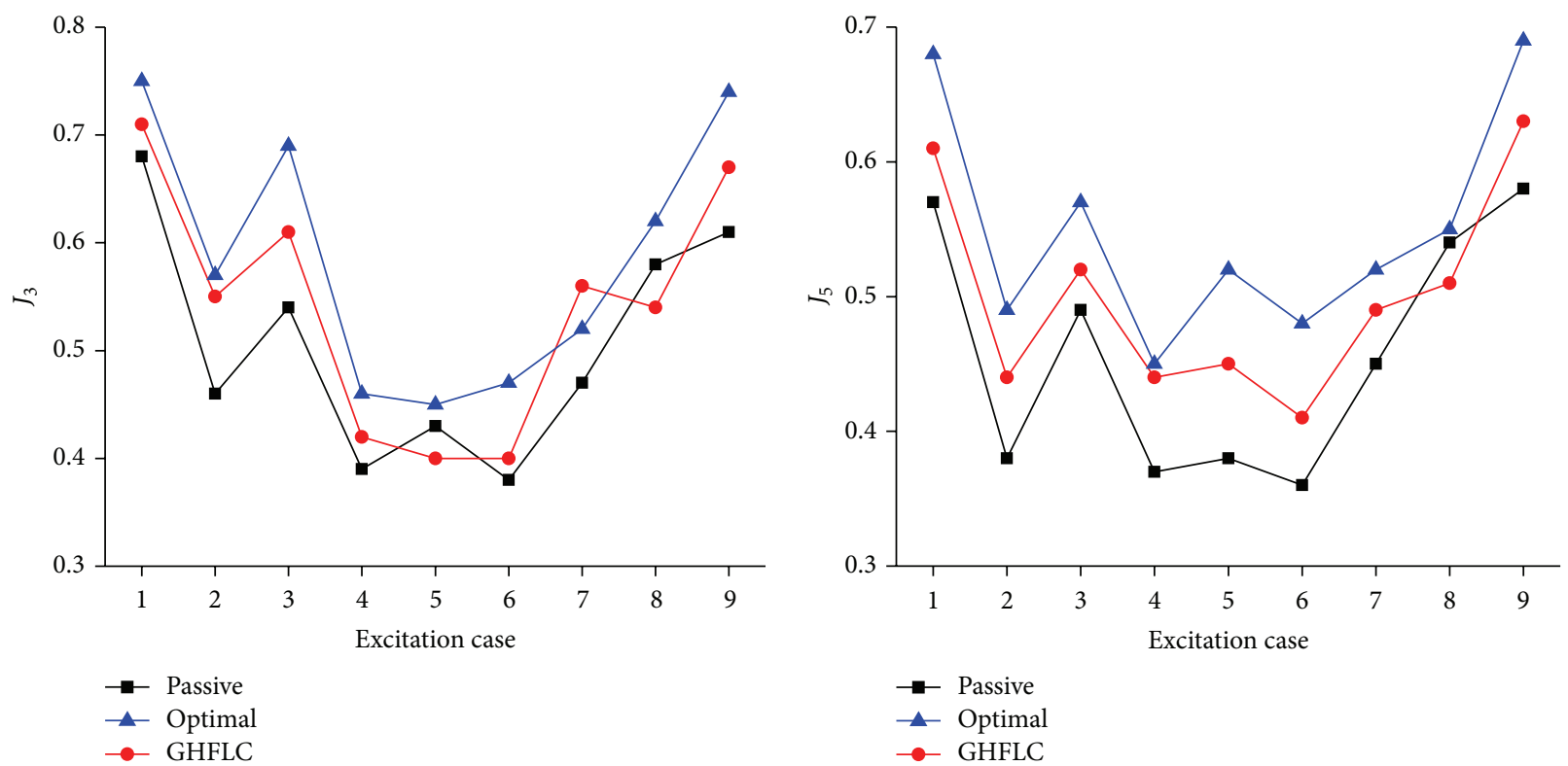

FIGURE 15: Comparisons on the performance indexes $J_{3}$ and $J_{7}$ for different control cases. 

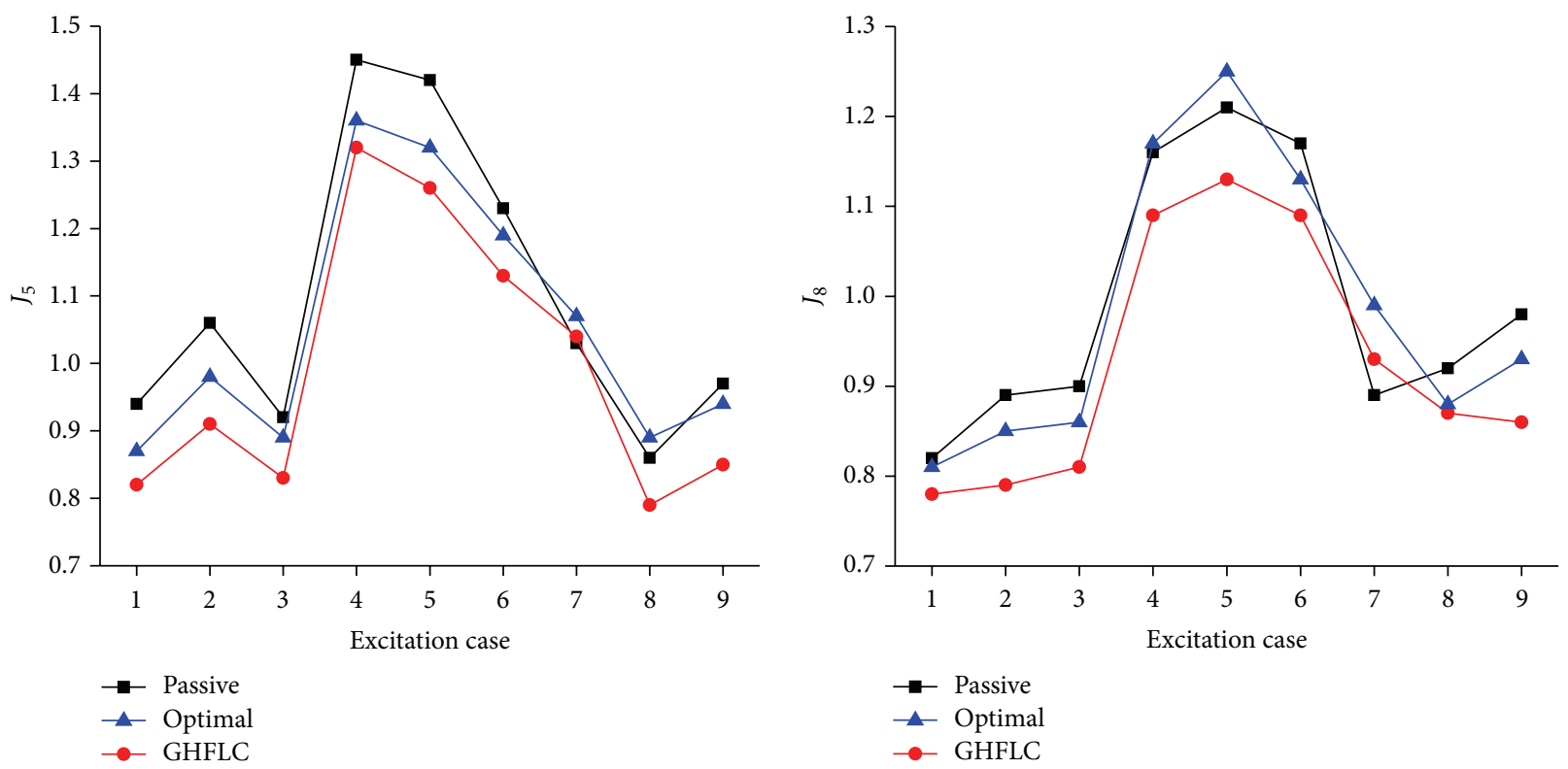

FIGURE 16: Comparison of the performance indexes $J_{5}$ and $J_{8}$ for different control cases.

with piezoelectric friction dampers installed on the isolation, the energy equations are defined as follows:

$$
\begin{aligned}
E_{K}+E_{\xi}+E_{S}+E_{H} & =E_{I}, \\
E_{K} & =\frac{1}{2} \dot{x}_{t}^{T} M \dot{x}_{t}, \\
E_{\xi} & =\int_{0}^{t} \dot{x}^{T} c \dot{x} d t, \\
E_{S} & =\int_{0}^{t} x^{T} K d x, \\
E_{H} & =-\int_{0}^{t} u^{T} E_{s}^{T} d x, \\
E_{I} & =-\int_{0}^{t} \ddot{x}_{\mathrm{g}} \mathrm{MI} d x,
\end{aligned}
$$

where $E_{K}, E_{\xi}, E_{S}, E_{H}$, and $E_{I}$ denote the absolute kinetic energy, damping energy, elastic strain energy, energy dissipated by piezoelectric friction dampers, and total input energy, respectively. The energy time histories for different controllers against TCU052 Chi-Chi earthquake are shown in Figure 17. It can be seen from the figures that the piezoelectric friction dampers dissipate most of the input energy for different control cases subjected to TCU052 earthquake.

In order to compare different effects under near-fault ground motions recorded for different sites, the average of input energy and structure responses subjected to near-fault earthquakes are given in Table 8.

As shown in Table 8, the near-fault earthquakes for soft sites are more destructive than hard sites. For instance, compared to hard sites, the input energy and the base displacement of RMS of the base-isolated structure for soft soil increase by $14.3 \%$ and $25.6 \%$, respectively. However, GHFLC possesses favorable performance under different ground sites, and the damping effect has no distinctly direct relationship with site category.

As discussed in Section 6.1, the isolation ratio of the simulation model equals 8.3 . In order to evaluate the effects of isolation ratio on the damping performance of GHFLC, the stiffness value of isolation is adjusted to 1045 and $452 \mathrm{kN} / \mathrm{m}$, respectively. Then, the numerical results for different values of isolation ratio $(\delta=4,6)$ are obtained. The performance indexes $J_{3}$ and $J_{5}$ for different isolation ratios are shown in Figures 18 and 19, respectively.

For base-isolated structure, isolation ratio has a significant influence on the isolation effect. A larger isolation ratio, which means a minor stiffness value of isolation, usually leads to conspicuous enlargement of base displacement and decrease of superstructural responses due to the increase of fundamental vibration period, and vice versa. However, as shown in Figures 18 and 19, the shock absorption rate of GHFLC has little change when isolation ratio varies differently and the proposed fuzzy control shows favorable effectiveness in the diverse isolation ratios of base-isolated structures.

\section{Conclusions}

In this study, an optimized fuzzy logic control which is designed for Chi-Chi near-fault earthquakes under different ground sites is proposed. An elastic design spectrum is proposed to generate near-fault earthquakes for different ground sites. The characteristic of the design spectrum is that it has larger periods and peak acceleration than conventional spectrum. Genetic algorithm is employed to optimize the supervisory fuzzy controller and preload of piezoelectric 
TABLE 8: Average ofinput energy and structure responses subjected to near-fault earthquakes.

\begin{tabular}{lcccc}
\hline Site classification & Input energy $(\mathrm{kN} \cdot \mathrm{m})$ & Base shear $(\mathrm{kN})$ & $\begin{array}{c}\text { Base displacement of } \\
\text { RMS }(\mathrm{m})\end{array}$ & $\begin{array}{c}\text { Structure acceleration } \\
\text { of RMS }(\mathrm{g})\end{array}$ \\
\hline Hard soil & 24375 & 47.5 & 0.047 & 0.432 \\
Medium soil & 26746 & 49.8 & 0.054 & 0.476 \\
Soft soil & 27857 & 56.8 & 0.059 & 0.531 \\
\hline
\end{tabular}

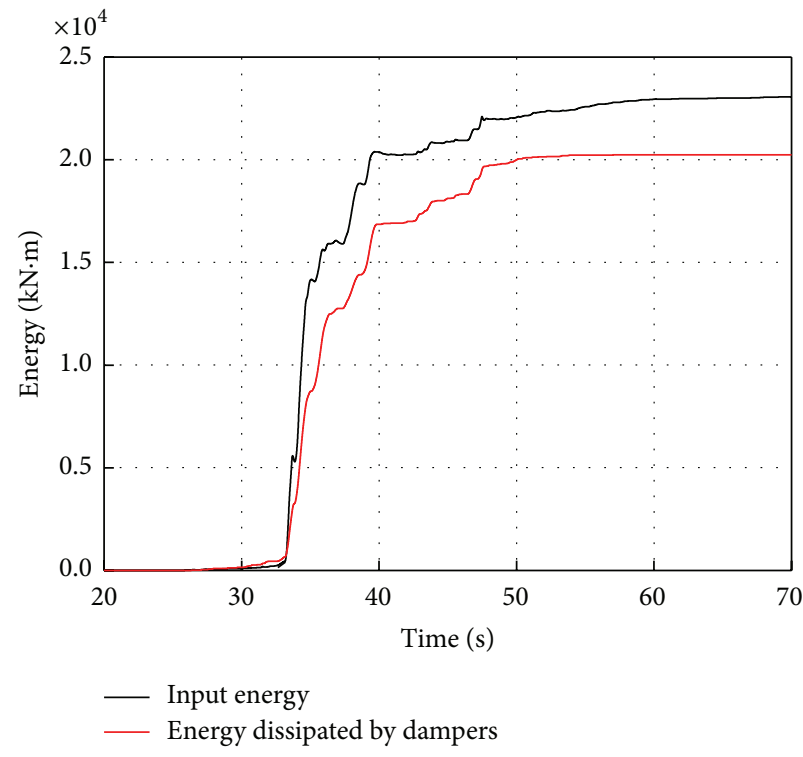

(a) Passive control

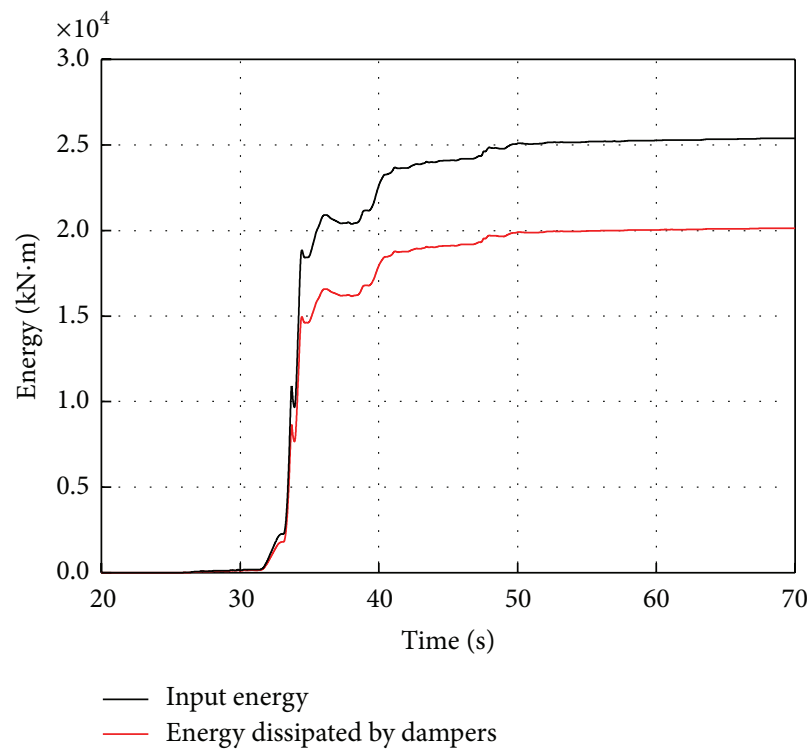

(b) Optimal control

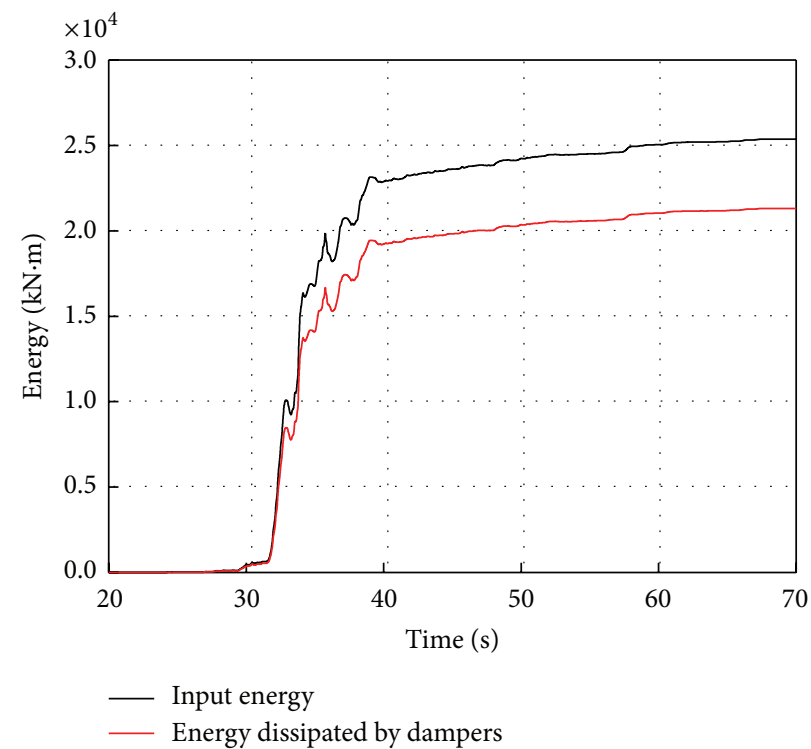

(c) GHFLC method

FIGURE 17: Energy time histories subjected to Chi-Chi TCU052 earthquake.

friction dampers according to three artificial earthquakes that are characterized by Chi-Chi earthquakes. Passive and optimal controllers are also compared with the performance of the developed fuzzy controller. The simulation results reveal that the developed semiactive fuzzy controller has better performance than traditional passive and optimal controller in simultaneously reducing the base displacement and floor acceleration under near-fault earthquakes for different ground sites.

\section{Conflict of Interests}

The authors declare no conflict of interests regarding the publication of this paper. 

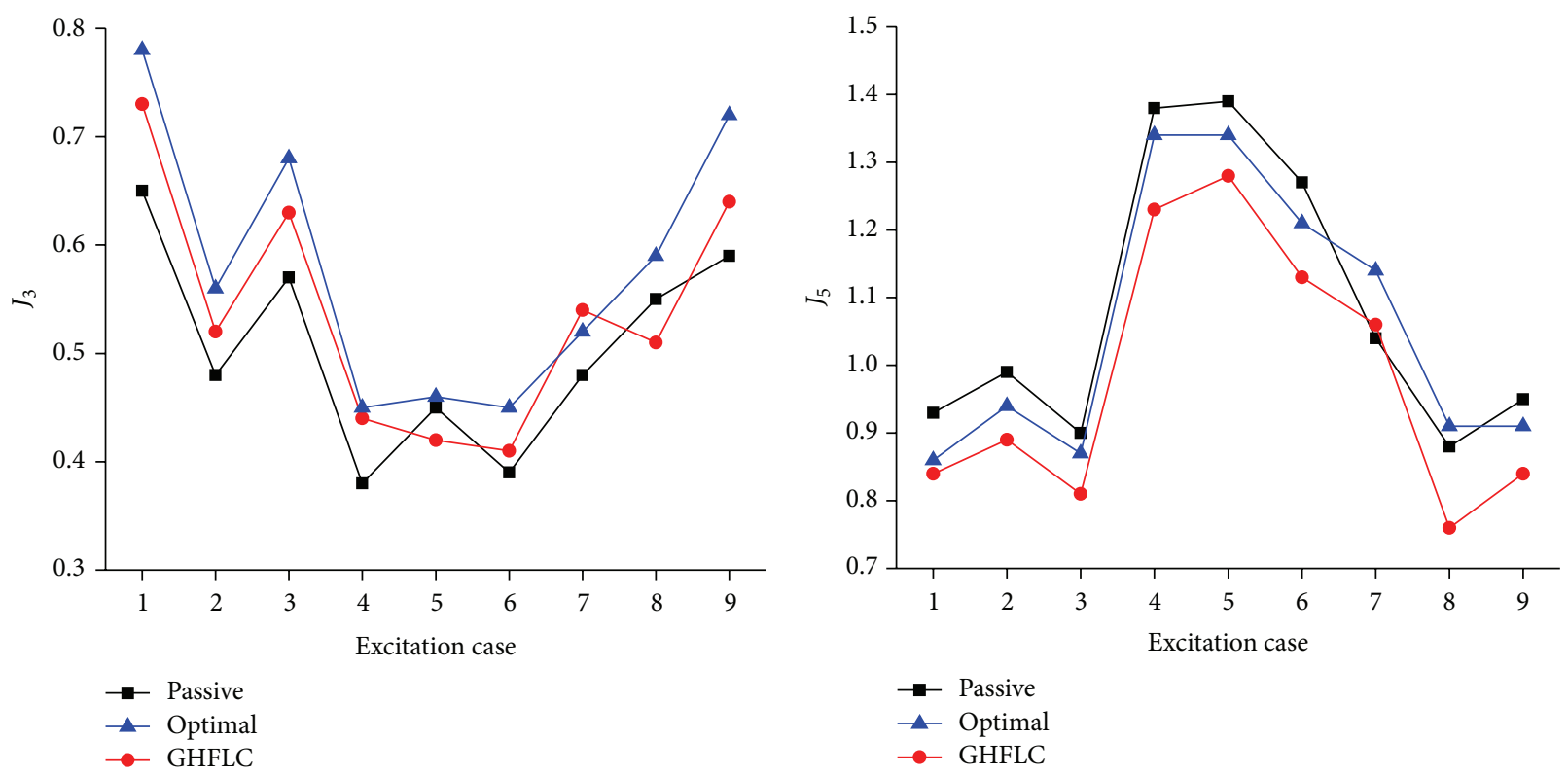

FIGURE 18: Comparisons on the performance indexes $J_{3}$ and $J_{5}$ for different control cases $(\delta=4)$.
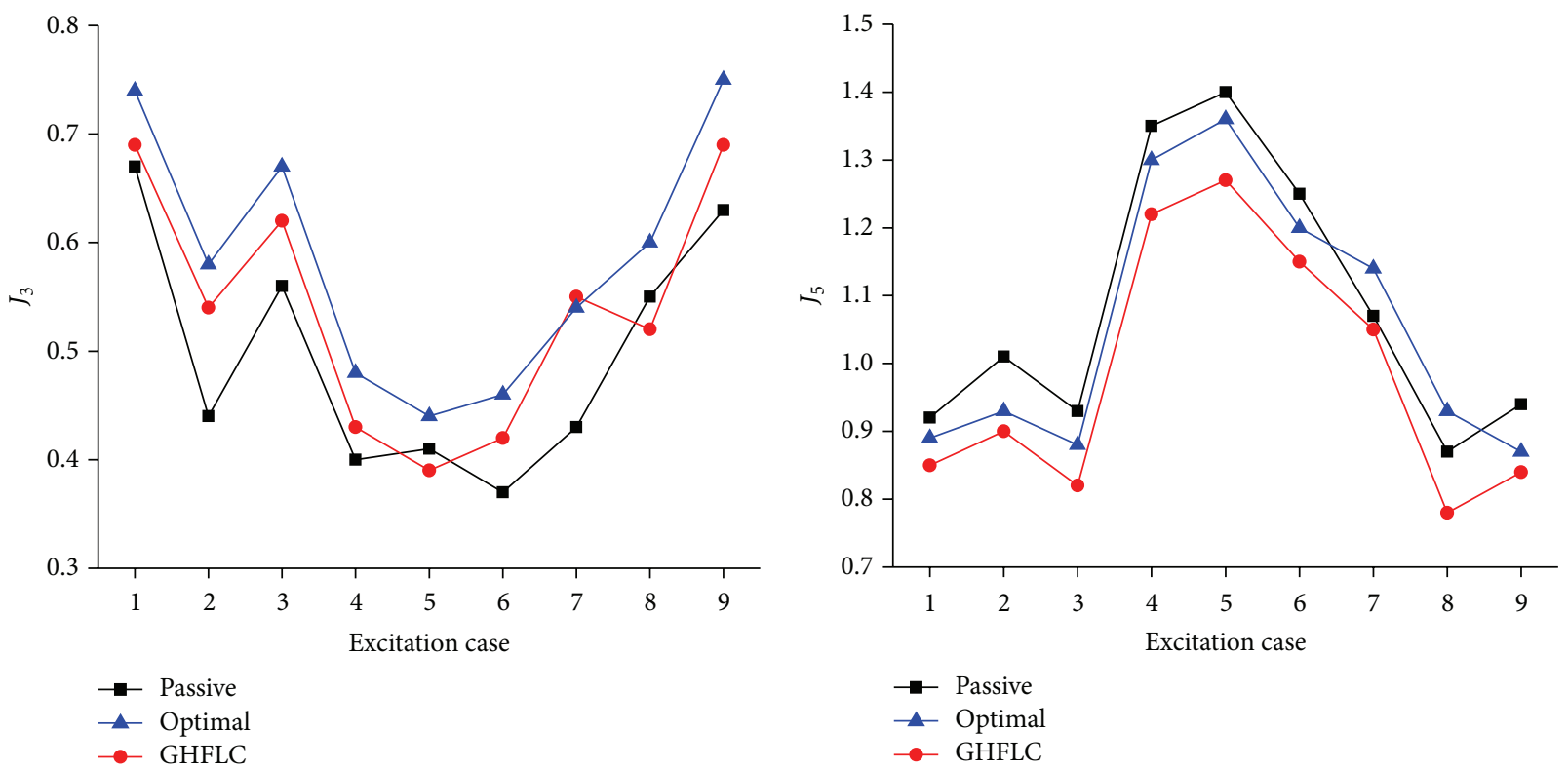

FIGURE 19: Comparisons on the performance indexes $J_{3}$ and $J_{5}$ for different control cases $(\delta=6)$.

\section{Acknowledgments}

This research was supported by National Natural Science Foundation of China under Grant no. 51308487, no. 41402261, and no. 51408526, Hebei Provincial Natural Science Foundation of China under Grant no. E2014203055, and the Excellent Youth Foundation of Hebei Educational Committee under Grant no. YQ2013015. The support for this research is greatly appreciated.

\section{References}

[1] C. Alhan and H. Gavin, "A parametric study of linear and nonlinear passively damped seismic isolation systems for buildings," Engineering Structures, vol. 26, no. 4, pp. 485-497, 2004.

[2] R. S. Jangid and J. M. Kelly, "Base isolation for near-fault motions," Earthquake Engineering and Structural Dynamics, vol. 30, no. 5, pp. 691-707, 2001.

[3] J. Shen, M.-H. Tsai, K.-C. Chang, and G. C. Lee, "Performance of a seismically isolated bridge under near-fault earthquake 
ground motions," Journal of Structural Engineering, vol. 130, no. 6, pp. 861-868, 2004.

[4] F. Mazza, A. Vulcano, and M. Mazza, "Nonlinear dynamic response of RC buildings with different base Isolation systems subjected to horizontal and vertical components of near-fault ground motions," Open Construction and Building Technology Journal, vol. 6, pp. 373-383, 2012.

[5] F. Mazza and A. Vulcano, "Effects of near-fault ground motions on the nonlinear dynamic response of base-isolated r.c. framed buildings," Earthquake Engineering and Structural Dynamics, vol. 41, no. 2, pp. 211-232, 2012.

[6] O. E. Ozbulut and S. Hurlebaus, "Fuzzy control of piezoelectric friction dampers for seismic protection of smart base isolated buildings," Bulletin of Earthquake Engineering, vol. 8, no. 6, pp. 1435-1455, 2010.

[7] O. E. Ozbulut, M. Bitaraf, and S. Hurlebaus, "Adaptive control of base-isolated structures against near-field earthquakes using variable friction dampers," Engineering Structures, vol. 33, no. 12, pp. 3143-3154, 2011.

[8] J. M. Kelly, "The role of damping in seismic isolation," Earthquake Engineering and Structural Dynamics, vol. 28, no. 1, pp. 3-20, 1999.

[9] F. Mazza and A. Vulcano, "Nonlinear response of RC framed buildings with isolation and supplemental damping at the base subjected to near-fault earthquakes," Journal of Earthquake Engineering, vol. 13, no. 5, pp. 690-715, 2009.

[10] M. Bitaraf and S. Hurlebaus, "Semi-active adaptive control of seismically excited 20-story nonlinear building," Engineering Structures, vol. 56, no. 11, pp. 2107-2118, 2013.

[11] D. Das, T. K. Datta, and A. Madan, "Semiactive fuzzy control of the seismic response of building frames with MR dampers," Earthquake Engineering and Structural Dynamics, vol. 41, no. 1, pp. 99-118, 2012.

[12] A.-P. Wang and C.-D. Lee, "Fuzzy sliding mode control for a building structure based on genetic algorithms," Earthquake Engineering and Structural Dynamics, vol. 31, no. 4, pp. 881-895, 2002.

[13] D. G. Reigles and M. D. Symans, "Supervisory fuzzy control of a base-isolated benchmark building utilizing a neuro-fuzzy model of controllable fluid viscous dampers," Structural Control and Health Monitoring, vol. 13, no. 2-3, pp. 724-747, 2006.

[14] H.-S. Kim and P. N. Roschke, "GA-fuzzy control of smart base isolated benchmark building using supervisory control technique," Advances in Engineering Software, vol. 38, no. 7, pp. 453-465, 2007.

[15] D. Yang and Y. Zhao, "Effects of rupture forward directivity and fling step of near-fault ground motions on seismic performance of base-isolated building structure," Acta Seismologica Sinica, vol. 32, no. 5, pp. 579-587, 2010.

[16] Y. E.-A. Mohamedzein, J. A. Abdalla, and A. Abdelwahab, "Site response and earthquake design spectra for central Khartoum, Sudan," Bulletin of Earthquake Engineering, vol. 4, no. 3, pp. 277293, 2006.

[17] D. Zhao and H. Li, "Shaking table tests and analyses of semiactive fuzzy control for structural seismic reduction with a piezoelectric variable-friction damper," Smart Materials and Structures, vol. 19, no. 10, Article ID 105031, 2010.

[18] W. L. He, A. K. Agrawal, and J. N. Yang, "Novel semiactive friction controller for linear structures against earthquakes," Journal of Structural Engineering, vol. 129, no. 7, pp. 941-950, 2003.
[19] J. N. Yang and A. K. Agrawal, "Semi-active hybrid control systems for nonlinear buildings against near-field earthquakes," Engineering Structures, vol. 24, no. 3, pp. 271-280, 2002.

[20] O. E. Ozbulut and S. Hurlebaus, "Optimal design of superelastic-friction base isolators for seismic protection of highway bridges against near-field earthquakes," Earthquake Engineering and Structural Dynamics, vol. 40, no. 3, pp. 273-291, 2011.

[21] D. A. Shook, P. N. Roschke, and O. E. Ozbulut, "Superelastic semi-active damping of a base-isolated structure," Structural Control and Health Monitoring, vol. 15, no. 5, pp. 746-768, 2008.

[22] K. D. Pham, G. Jin, M. K. Sain, B. F. Spencer Jr., and S. R. Liberty, "Generalized linear quadratic Gaussian techniques for the wind benchmark problem," Journal of Engineering Mechanics, vol. 130, no. 4, pp. 466-470, 2004.

[23] S. Nagarajaiah and S. Narasimhan, "Smart base-isolated benchmark building. Part II. Phase I sample controllers for linear isolation systems," Structural Control and Health Monitoring, vol. 13, no. 2-3, pp. 605-625, 2006. 


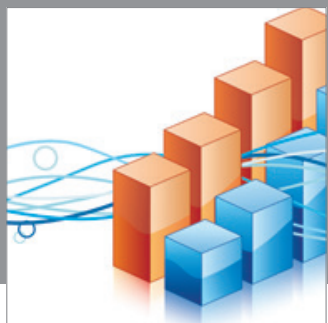

Advances in

Operations Research

mansans

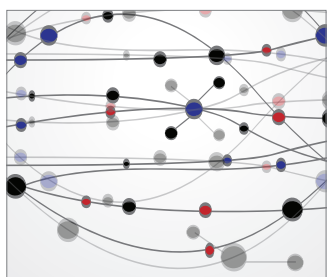

The Scientific World Journal
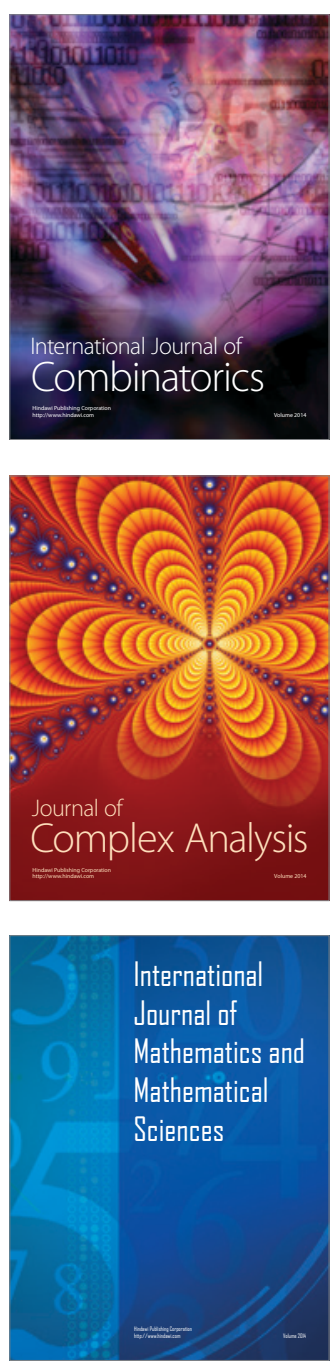
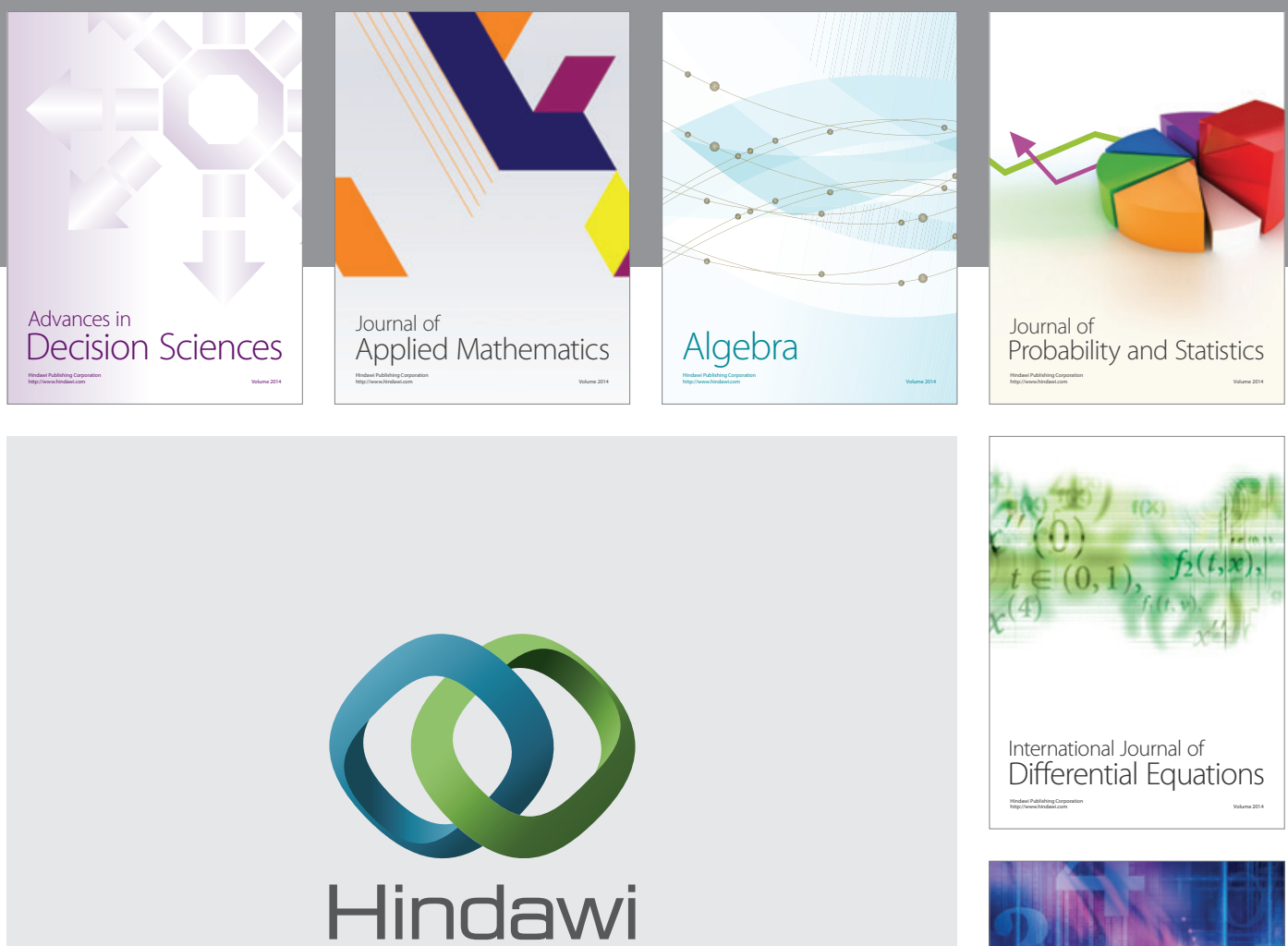

Submit your manuscripts at http://www.hindawi.com
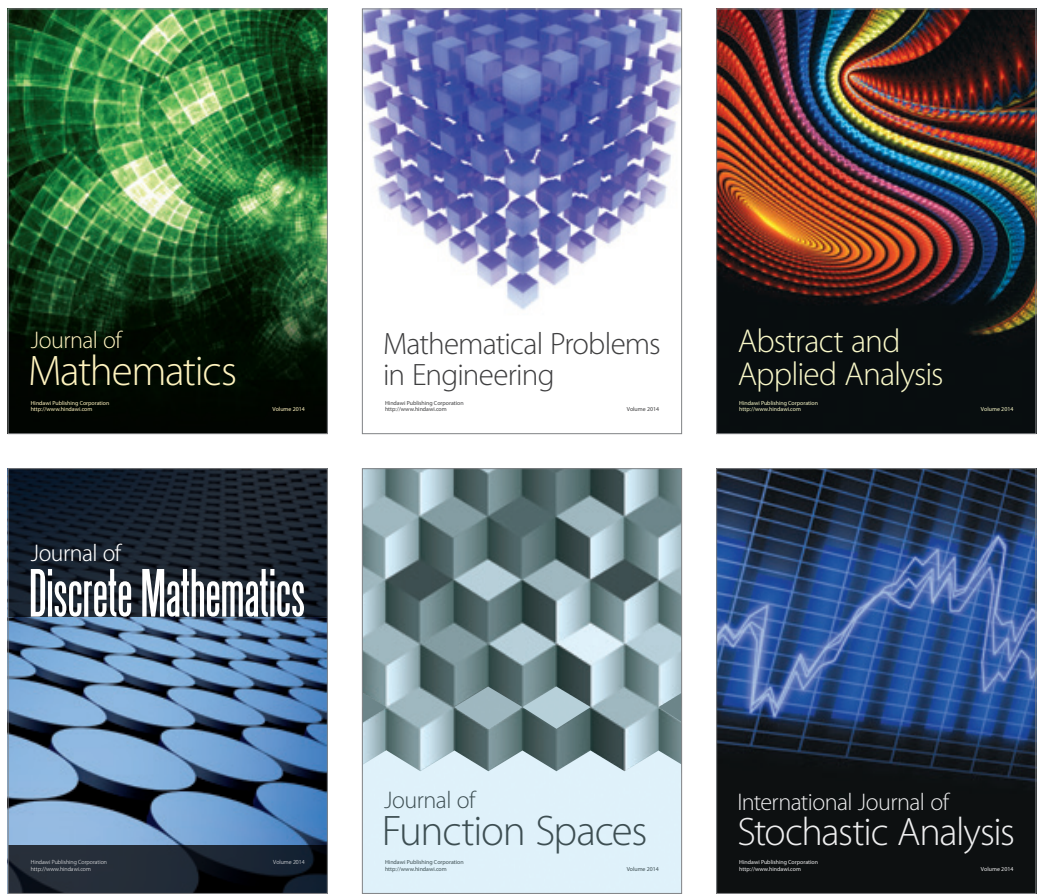

Journal of

Function Spaces

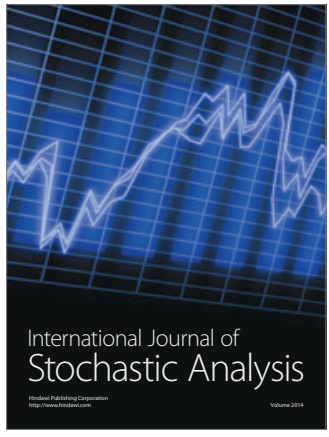

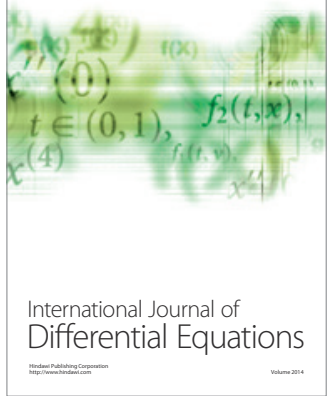
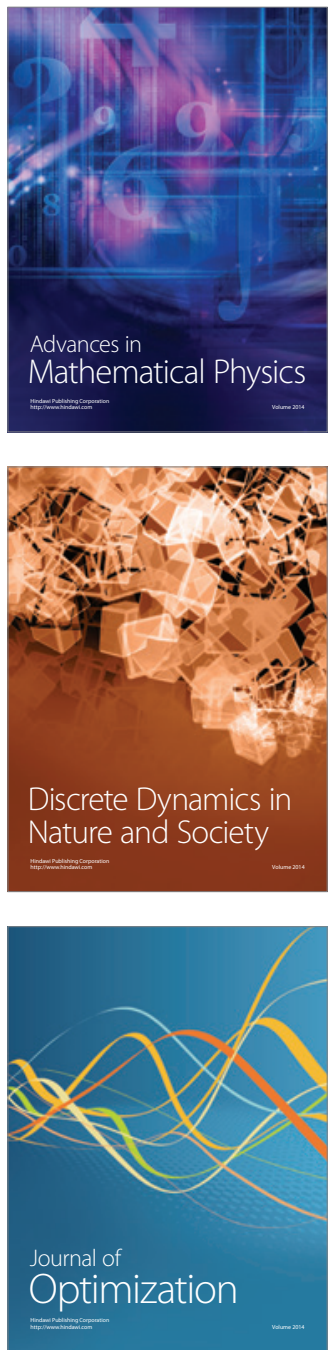